\title{
Management of Lower Extremity Pain from Chronic Venous Insufficiency: A Comprehensive Review
}

\author{
Vwaire Orhurhu • Robert Chu - Katherine Xie - Ghislain N. Kamanyi • \\ Bisola Salisu • Mariam Salisu-Orhurhu • Ivan Urits • Rachel J. Kaye • \\ Jamal Hasoon · Omar Viswanath · Aaron J. Kaye · Jay Karri • \\ Zwade Marshall · Alan D. Kaye · Dua Anahita
}

Received: September 14, 2020 / Published online: March 11, 2021

(C) The Author(s) 2021

\begin{abstract}
Purpose of Review: Chronic venous insufficiency is found to some extent in a large proportion of the world's population, especially in the elderly and obese. Despite its prevalence, little research has been pursued into this pathology when compared to similarly common conditions. Pain is often the presenting symptom of chronic venous insufficiency and has significant deleterious effects on quality of
\end{abstract}

V. Orhurhu $(\bowtie) \cdot$ M. Salisu-Orhurhu

Department of Anesthesia, Critical Care and Pain

Medicine, Massachusetts General Hospital, Harvard

Medical School, Boston, MA, USA

e-mail: vwo569@mail.harvard.edu

R. Chu

Johns Hopkins School of Medicine, Baltimore, MA, USA

K. Xie

Mayo Clinic College of Medicine, Rochester, MN, USA

G. N. Kamanyi · B. Salisu

Meharry Medical College, Nashville, TN, USA

I. Urits · J. Hasoon

Department of Anesthesia, Critical Care and Pain Medicine, Beth Israel Deaconess Medical Center, Harvard Medical School, Boston, MA, USA

R. J. Kaye - A. J. Kaye

Medical University of South Carolina, Charleston, SC, USA life. This manuscript will describe the development of pain in chronic venous insufficiency, and will also review both traditional methods of pain management and novel advances in both medical and surgical therapy for this disease.

Recent Findings: Pain in chronic venous insufficiency is a common complication which remains poorly correlated in recent studies with the clinically observable extent of disease. Although lifestyle modification remains the foundation of treatment for pain associated

\section{O. Viswanath · A. D. Kaye}

Department of Anesthesiology, Louisiana State

University Health Shreveport Shreveport,

Shreveport, LA, USA

O. Viswanath

University of Arizona College of Medicine-Phoenix, Phoenix, AZ, USA

O. Viswanath

Valley Anesthesiology and Pain

Consultants-Envision Physician Services, Phoenix, AZ, USA

O. Viswanath

Department of Anesthesiology, Creighton University School of Medicine, Omaha, NE, USA

\section{J. Karri}

Department of Physical Medicine and

Rehabilitation, Baylor College of Medicine, Houston, TX, USA

\section{Z. Marshall}

Regenerative Spine and Pain Specialist, Fayetteville, GA, USA 
with chronic venous sufficiency, compression devices and various pharmacologic agents have emerged as safe and effective treatments for pain in these patients. In patients for whom these measures are insufficient, recently developed minimally invasive vascular surgical techniques have been shown to reduce postsurgical complications and recovery time, although additional research is necessary to characterize long-term outcomes of these procedures.

Summary: This review discusses the latest findings concerning the pathophysiology of pain in chronic venous insufficiency, conservative and medical management, and surgical strategies for pain relief, including minimally invasive treatment strategies.

Keywords: Chronic venous insufficiency; Conservative pain management; Minimally invasive surgery; Vein surgery

\section{Key Summary Points}

Chronic venous insufficiency (CVI) and varicose veins of the lower extremity are common yet understudied conditions in the general population. Estimations of the true prevalence of varicose veins have varied widely, from less than $1 \%$ to upwards of $70 \%$, and between 1 and $40 \%$ for CVI, depending on the population surveyed and the definition of disease.

This manuscript describes the pathophysiology and symptoms associated with chronic venous insufficiency. In addition, we describe the traditional methods of pain management as well as novel advances in both medical and surgical therapy for chronic venous insufficiency.

D. Anahita

Division of Vascular and Endovascular Surgery, Massachusetts General Hospital, Harvard Medical School, Boston, MA, USA
Pain in chronic venous insufficiency is a common complication. Although lifestyle modification remains the foundation of treatment for pain associated with chronic venous sufficiency, compression devices, various pharmacologic agents, and minimally invasive vascular procedures have emerged as safe and effective treatments for pain in these patients.

This review describes the latest findings concerning the pathophysiology of pain in chronic venous insufficiency, conservative and medical management, and surgical strategies for pain relief, including minimally invasive treatment strategies.

\section{DIGITAL FEATURES}

This article is published with digital features, including a summary slide, to facilitate understanding of the article. To view digital features for this article go to https://doi.org/10.6084/ m9.figshare.13622657.

\section{INTRODUCTION}

\section{Epidemiology and Risk Factors}

Chronic venous insufficiency (CVI) and varicose veins of the lower extremity are common yet understudied conditions in the general population. Estimations of the true prevalence of varicose veins have varied widely from less than $1 \%$ to upwards of $70 \%$, and between 1 and $40 \%$ for CVI, depending on the population surveyed and the definition of disease $[1,2]$. Quantification of the prevalence of CVI is complicated by the wide range of clinical presentations of disease, which can range from purely cosmetic stigmata to serious complications, including venous stasis, ulceration, and venous embolism. Studies that distinguish between categories of severity have estimated 
the prevalence of clinically serious venous disease at approximately $15-25 \%[3,4]$.

Risk factors for CVI and varicose veins include age, gender, ethnic, and lifestyle factors. The exact effect of age on risk for CVI and varicose veins varies based on the study population, but risk for these diseases uniformly has been shown to increase with age $[1,5]$. A crossethnic study of patients in San Diego found that only $7.4 \%$ of subjects over the age of 70 were free of visible signs of venous disease, compared to $33.0 \%$ of subjects under age 50 [3]. Risk for trophic changes (e.g., hyperpigmentation, lipodermatosclerosis, or ulceration) related to CVI has been shown to display a more marked increase with age compared to the risk of merely varicose veins and/or telangiectasias [6].

Gender has also been demonstrated as a risk factor for CVI and varicose veins, with higher rates of varicose veins apparent in females $[1,3,7,8]$. The relation between gender and CVI is less straightforward. Population-level analyses in the Edinburgh Vein Study found increased prevalence of CVI among male subjects, although this difference was only apparent in the oldest age cohort (55-64 years) [2]. Similarly, the San Diego study found increased prevalence of trophic changes among male subjects compared to females $(7.8 \%$ vs. $5.3 \%)$. However, there is still a lack of a consensus on CVI prevalence by gender, as several studies have demonstrated higher rates in women, as well as increased symptomatic complaints of venous disease, compared to men [1, 9-12]

Several other risk factors have also been demonstrated. In the cross-ethnic San Diego study, White patients had the highest rates of trophic changes indicative of CVI, while Hispanic patients had the highest rates of varicose veins [13]. Family history of venous disease, as well as personal history of deep venous thrombosis (DVT) or lower extremity injury, has been shown to increase an individual's lifetime risk $[8,14]$. Rates of CVI and varicose veins are increased in the developed world, as well as among overweight and obese patients, especially women $[8,15,16]$. Among women, increasing parity and oophorectomy have been associated with higher risk for varicose veins $[6,17,18]$. Several studies have shown increased rates of venous disease (either symptomatic or detected via imaging) among subjects who report spending significant amounts of time standing as part of their job [19-21]. Additional factors that have been suggested as possible risk factors in small numbers of studies include tobacco smoking and nonuse of oral contraceptives and/or hormone replacement therapy $[18,22]$. This review article is a de-identified overview that contains factual information.

This article is based on previously conducted studies and does not contain any new studies with human participants or animals performed by any of the authors. The review article does not require institutional review board (IRB) approval or exempt determination. This review article does not directly involve "human subjects" as defined by federal regulations and guidance (https://www.hhs.gov/ohrp/ regulations-and-policy/regulations/commonrule/index.html). Thus, all procedures performed were in accordance with the ethical standards of the institutional and/or national research committee and with the 1964 Helsinki declaration and its later amendments or comparable ethical standards.

\section{Pathophysiology of Venous Disease}

The superficial and deep venous systems of the lower extremity are connected by a series of perforator veins. Under normal conditions, valves within the veins ensure that no retrograde flow, or reflux, occurs within the veins as the calf muscle pumps blood back towards the heart [23, 24]. Mechanical obstruction or valvular incompetence can cause pooling of blood in the lower extremity, leading to a phenomenon known as venous hypertension.

Superficial venous hypertension may result from either primary valvular incompetence due to an as-yet-undetermined etiology or perforator incompetence due to deep vein hypertension [24]. The result is the classic symptomatology associated with venous disease, including the appearance of varicosities as veins are engorged with refluxed blood $[20,24,25]$. Subsequent extravasation of macromolecules and red blood cells leads to 
edema with an inflammatory response and subsequent leukocyte invasion, causing the characteristic dermal changes of hyperpigmentation, ulceration, and eventual fat necrosis and fibrotic change, termed lipodermatosclerosis $[26,27]$.

DVT, together with pulmonary embolism (PE), constitutes manifestations of venous thromboembolism. Rudolf Virchow describes three factors that are critical to the development of venous thrombosis: (1) venous stasis, (2) hypercoagulable state, and (3) vein damage. DVT is the presence of a thrombus in any portion of the peripheral circulation returning blood to the heart. DVT most commonly involves the deeps veins of the legs or arms, but has been demonstrated to form in splanchnic veins and cerebral veins as well. Lower extremity DVT is the most common venous thrombosis, with approximately 80 cases per 100,000 population annually. Additionally, about 400,000 hospitalizations in the United States can be tied directly to DVT each year, resulting in an economic burden estimated to be in the range of US\$7-10 billion [28]. Besides PE, another major complication is post-thrombotic syndrome (PTS), which usually manifests several years after the initial event. It is a long-term complication of DVT with symptoms ranging from a mild erythema to massive swelling and ulceration, which in many cases results in CVI [29]. Due to non-standardized reporting, it is difficult to ascertain the incidence of improvements with therapy and to measure hemodynamic changes correlated with severity of PTS [30].

\section{Clinical Presentation}

The spectrum of disease presentation for CVI is broad. Initial signs of disease may include the appearance of telangiectasias (spider veins) and reticular veins. These findings are quite common and were shown to be present in $>80 \%$ of the population in the Edinburgh Vein Study [2]. Physical findings progress further to varicose veins, followed by leg edema; the latter of these findings confirms the onset of CVI [31]. Edema leads sequentially to venous stasis and the dermatologic complications of venous ulceration by the mechanism described earlier. The same Edinburgh study found a prevalence of ankle edema of $7 \%$ in men and $16 \%$ in women, and ulceration in approximately $1 \%$ of the general population [2].

Patient-reported symptoms of CVI may include ache-like or cramping pain, a feeling of "heavy legs" or swelling, paresthesias, and pruritus [32]. One study of CVI patients in Belgium and Luxembourg showed that the most common symptom was heaviness in the legs, which was present in $70 \%$ of patients, while approximately $50 \%$ experienced pain and $20 \%$ pruritus or paresthesia. Of the symptomatic patients, $75 \%$ experienced two or more symptoms [12]. The occurrence of these symptoms increases with stage of disease; in another study, only approximately $25 \%$ patients with the earliest stage of disease reported symptoms, compared to a symptomatic prevalence of $>70 \%$ in middle- and late-stage disease [33]. Progression from early stages of disease such as varicose veins to frank CVI is common and occurred among $31.9 \%$ of patients in the Edinburgh Vein Study at 13-year followup, with clinical deterioration occurring in nearly all patients surveyed [34].

CVI, especially late-stage disease, can lead to serious deterioration of quality of life. Assessment of participants in the San Diego vein study using the 36-item Short Form Survey (SF-36) questionnaire showed markedly diminished quality of life in the physical function, pain, and general health perception domains which was strongly correlated with disease severity [35]. Patients with chronic leg ulcers reported difficulty with pain, hygiene, mobility, and social interaction [36]. The socioeconomic impact of CVI is large; treatment of the disease accounts for approximately 1-3\% of the entire healthcare budget in developed countries $[32,37,38]$.

\section{Diagnosis and Classification}

Diagnosis of CVI can be accomplished by a meticulous patient history and physical exam combined with imaging methods (Table 1). The lower extremities should be examined for 
superficial stigmata of venous disease such as telangiectasia or varicose veins, as well as dermal changes consistent with venous stasis and edema. The Brodie-Trendelenburg test may be performed to differentiate between deep and superficial reflux: the patient is placed in the supine position and the superficial veins are compressed with a tourniquet or manually. Upon standing, patients with superficial reflux will take greater than $20 \mathrm{~s}$ to refill varicose veins, while this refilling will occur more quickly in patients with deep reflux [23,39].

Duplex ultrasound (B-mode plus spectral Doppler with possible color Doppler supplementation) is the first-line imaging test to evaluate CVI [39]. Both reflux and obstruction can be visualized using this modality. Supplemental modalities, such as intravascular ultrasound or plethysmography, can be used to further characterize the venous system of the lower leg.

The gold-standard classification system for CVI is the Clinical-Etiologic-Anatomic-Pathophysiologic (CEAP) classification [40]. In general clinical practice, the " $\mathrm{C}$ " classification is the most relevant; patients can be classified on a spectrum as $\mathrm{C}_{0}$ (no visible or palpable disease), $\mathrm{C}_{1}$ (telangiectasias or reticular veins), $\mathrm{C}_{2}$ (varicose veins), $\mathrm{C}_{3}$ (edema), $\mathrm{C}_{4 \mathrm{~A}}$ (skin pigmentation), $\mathrm{C}_{4 \mathrm{~B}}$ (lipodermatosclerosis or atrophie blanche), $\mathrm{C}_{5}$ (healed ulcer), or $\mathrm{C}_{6}$ (active ulcer), with the signifier $\mathrm{A}$ or $\mathrm{S}$ appended to denote asymptomatic or symptomatic patients $[23,28,40]$. Most clinical studies of CVI report patient disease severity using the CEAP scale.

\section{Differential Diagnosis of Chronic Extremity Pain}

It is important to consider other possible diagnoses for patients with chronic lower extremity pain. Other possible etiologies include claudication and other arterial diseases, neuronal or vascular entrapment following trauma, or peripheral pain syndromes such as complex regional pain syndrome (CRPS). Exertional musculoskeletal causes such as shin splints, chronic compartment syndrome, or stress fracture may be considered, especially in physically active patients [41].

\section{PAIN IN VENOUS DISEASE}

Pain is a very common symptom in CVI. Classically described as an aching or cramping pain, its prevalence in patients with CVI has been estimated from 15 to $70 \%$, depending on the population being studied [16, 42, 43]. The average visual analogue score in one study investigating CVI in postmenopausal women was found to be 5.44, with a standard deviation of 2.5 [44]. Thus, pain presents a major qualityof-life issue in patients with CVI. Indeed, one study reported that pain was identified as a significant detrimental factor in quality of life among patients with CEAP class C3 or worse compared to controls [45].

The venous system is innervated by afferent fibers originating from the dorsal root ganglion. These fibers, which are predominantly $\mathrm{A} \delta$ myelinated fibers, both penetrate the vein to innervate the subendothelial space and spread in the perivascular space to innervate connective tissue [46-48]. These afferent fibers receive their nociceptive input from polymodal nociceptive receptors; as a result, noxious stimuli of several different types-electrical, stretch, thermal, and osmotic - were shown to elicit a similar sharp, aching pain sensation [46].

Current hypotheses explaining the pathogenesis of pain in CVI center on a proposed inflammatory response to venous incompetence. The initial insult is venous stasis, causing local hypoxia as well as abnormal shear stresses, which subsequently activate the release of inflammatory mediators and growth factors from endothelial cells $[49,50]$. These inflammatory markers include adhesion molecules, cytokines, pro-thrombotic agents (von Willebrand factor), and prostaglandins (prostaglandin E1, prostaglandin I2) [47, 49, 51]. These inflammatory markers are theorized to sensitize and activate venous nociceptors, causing the characteristic pain of CVI. Interestingly, however, no relation has been shown between the levels of these inflammatory 
Table 1 CEAP classification of chronic venous insufficiency

\begin{tabular}{|c|c|c|c|}
\hline C & $\mathbf{E}$ & $\mathbf{A}$ & $\mathbf{P}$ \\
\hline Clinical $^{\mathrm{a}}$ & Etiology & Anatomic & Pathophysiologic ${ }^{b}$ \\
\hline $\mathrm{C}_{0}$ : No signs of venous disease & $\mathrm{E}_{\mathrm{c}}$ : congenital & $\begin{array}{l}\mathrm{A}_{\mathrm{s}} \text { : superficial } \\
\text { veins }\end{array}$ & $\mathrm{P}_{\mathrm{r}}:$ reflux \\
\hline $\mathrm{C}_{1}$ : Telangiectasias or reticular veins & $\mathrm{E}_{\mathrm{p}}:$ primary & $\begin{array}{l}A_{p}: \text { perforator } \\
\text { veins }\end{array}$ & $\mathrm{P}_{\mathrm{o}}$ : obstruction \\
\hline $\begin{array}{l}\mathrm{C}_{2}: \text { Varicose veins } \\
\mathrm{C}_{2 \mathrm{r}}: \text { Varicose veins, recurrent }\end{array}$ & $\begin{array}{l}\mathrm{E}_{\mathrm{s}}: \text { secondary } \\
\mathrm{E}_{\mathrm{si}}: \text { secondary- } \\
\text { intravenous } \\
\mathrm{E}_{\mathrm{se}}: \text { secondary- } \\
\text { extravenous }\end{array}$ & $A_{d}:$ deep veins & $\begin{array}{c}\mathrm{P}_{\mathrm{r}, \mathrm{o}}: \text { reflux and } \\
\text { obstruction }\end{array}$ \\
\hline $\mathrm{C}_{3}:$ Edema & $\mathrm{E}_{\mathrm{n}}$ : not identified & $A_{n}:$ not identified & $\mathrm{P}_{\mathrm{n}}$ : not identified \\
\hline \multicolumn{4}{|l|}{$\mathrm{C}_{4}:$ Skin changes } \\
\hline \multicolumn{4}{|l|}{$\mathrm{C}_{4 \mathrm{a}}$ : Pigmentation or eczema } \\
\hline \multicolumn{4}{|l|}{$\begin{array}{l}\mathrm{C}_{4 \mathrm{~b}}: \text { Lipodermatosclerosis or atrophie } \\
\text { blanche }\end{array}$} \\
\hline \multicolumn{4}{|l|}{$\mathrm{C}_{4 \mathrm{c}}:$ Corona phlebectatica } \\
\hline \multicolumn{4}{|l|}{$\mathrm{C}_{5}:$ Healed ulcer } \\
\hline \multicolumn{4}{|l|}{$\mathrm{C}_{6}:$ Active ulcer } \\
\hline $\mathrm{C}_{6 \mathrm{r}}:$ Active ulcer, recurrent & & & \\
\hline
\end{tabular}

a The designators S (symptomatic) and A (asymptomatic) are further applied to each C classification

b Advanced CEAP classification specifies one of 18 specific venous locations in the lower extremity

mediators and patient self-reported symptoms in CVI [52].

Recently, more attention has been placed on neuropathy and neuropathic pain in CVI. Patients with CVI have been found to have higher rates of lower extremity neuropathic symptoms, including burning, paresthesia, and decreased sensation, than similar controls $[53,54]$. Nerve testing in CVI patients without risk for neuropathy from other causes showed decreased function in $A \beta, A \delta$, and $C$ nerve fibers [55]. Hypotheses for the pathogenesis of nerve damage in CVI include venous microangiopathy and increased endoneurial pressure resulting from venous stasis [55]. Similarly to patients with diabetes mellitus, peripheral nerve damage in patients with CVI may play a role in the development of venous ulceration $[54,55]$.

The relation between clinical progression of CVI in terms of venous reflux and patient-reported pain has been difficult to fully define. Analysis of self-reported symptoms among participants in the Edinburgh Vein Study found little if any correlation between the extent of venous reflux detected on duplex ultrasound and patient-reported pain [56]. In a study of itch-associated symptoms in CVI, both itch and burning sensation were found to have no correlation with the extent of venous insufficiency as graded by CEAP score [57]. Similarly, another study showed no relationship between $C$ stage and VAS pain scores, and in fact reported that 
$\mathrm{C}_{2}-\mathrm{C}_{3}$ patients had more severe symptoms than patients with more advanced disease, and very few lower limb symptoms were seen at all in patients with advanced $\left(\mathrm{C}_{5}\right)$ disease [52]. The authors attributed this finding to possible peripheral neuropathy that developed in severe venous disease. Other explanations for the seeming absence of correlation may include nociception in structures outside of the vein itself, such as in the microvasculature, or individual differences in inflammatory response or pain perception [47].

However, this finding is not universal among studies. One Italian study found that increasing prevalence of pain correlated with advancing $\mathrm{C}$ stage, even at higher $\left(\mathrm{C}_{4}-\mathrm{C}_{6}\right)$ disease severities [58]. Uniquely from other symptoms of CVI, this observation held only in women, and not in men, even though a stronger relationship between superficial signs of disease and functional reflux was observed in the latter. In fact, age and gender have been identified as risk factors for the presence of CVI symptoms [59]. Additionally, results from a German study found increasing $\mathrm{C}$ stage to be associated with increased prevalence of pain after standing, but not after walking [59].

\section{ADVANCES IN NONSURGICAL MANAGEMENT: CONSERVATIVE}

Initial management of CVI pain involves conservative approaches that aim to reduce the associated symptoms (e.g. ulcers, which are often painful and exudative) and prevent complications associated with further progression of disease. They include lifestyle modification (e.g. leg elevation, exercise) and compressive therapies aimed mainly at restoring venous physiological function in the affected extremity. Although all patients should incorporate lifestyle changes into their treatment, these interventions may be especially appropriate for patients who are not candidates for medical or surgical treatment, those who refuse medical or surgical management, and those who are pregnant [8].

\section{Leg Elevation}

The pain and associated anatomic, physiologic, and histologic symptoms resulting from CVI arise with venous hypertension. Overcoming the effects of gravity in the affected extremity via simple leg elevation results in a drop in venous pressures and can serve as effective primary treatment and lead to the resolution of symptoms associated with CVI, especially in patients with less severe disease [60]. Elevating the feet to at/above heart level for 30 min three to four times a day has been shown to improve cutaneous microcirculation, heal ulcers, and reduce edema [60-62]. Studies that induced venous stasis in healthy volunteers via casting also demonstrated decreased intramuscular pressures with leg elevation [63, 64]. Although these studies were focused on compartment syndrome, decreasing intramuscular pressure may also play a role in relieving the pain associated with venous stasis. For patients with more severe cases of CVI, leg elevation alone may not be sufficient to relieve symptoms and can be used in conjunction with other therapy protocols.

\section{Exercise}

A key physiologic mechanism for return of venous blood from the lower extremity to the heart is the calf muscle pump. Decreased vein emptying due to impaired efficiency of the calf muscle pump results in ambulatory venous hypertension that contributes to the pain and associated symptoms such as ulcers in CVI [65]. The goal of physiotherapy is to treat these symptoms by restoring the physiologic function of the calf muscle pump. When ankle joint motility was artificially restricted in healthy volunteers, there was a significant decrease in the efficacy of the calf muscle-vein pump [66]. Conversely, ankle movement in healthy volunteers increased peak velocity of blood flow in both the popliteal and femoral veins, suggesting that venous stasis may be forestalled by exercise $[67,68]$. Specifically, ankle dorsiflexion, ankle plantarflexion, and forceful toe flexion were found to be the most effective movements for 
increasing systolic blood velocity [69]. Given that the ankle joint is a main component of the pump, prescribed physical activity involving ankle mobility (walking, treadmill, cycling) and dorsiflexion and plantar flexion exercises of the ankle have been demonstrated as effective symptom management in patients with less severe disease $[60,70,71]$. Specifically, randomized prospective trials demonstrate improved calf pump function, hemodynamic parameters, and ulcer healing compared to baseline following 8-12 weeks of structured exercise regimens focused on leg strengthening for at least $30 \mathrm{~min}$ three times a week [70-75]. Symptomatic improvement in feelings of lower extremity heaviness, as well as physiologic reduction in lower limb volume, was achieved after five 50-min sessions of aquatic exercise, which may be more achievable for patients with other disease processes (e.g., osteoarthritis) who may have difficulty completing land-based exercise activity [76]. Even participation in regular sports activities has been shown to decrease risk of venous thrombosis, suggesting that physical activity that is not specifically targeted at the lower extremity veins may help relieve symptoms and prevent the underlying disease process of CVI [77].

\section{Compression Therapy}

Compression therapy is another key standard procedure indicated in the conservative management of advanced chronic venous disease involving pain due to ulceration, edema, and skin changes. Most fundamentally, compression therapy involves providing external mechanical force to the affected limb with the aim of healing ulcers, reducing edema, lipodermatosclerosis, and the associated pain. Application of force on the area surrounding the insufficiency changes the tissue pressure gradient and promotes physiological drainage of the edema [78]. Specifically, compression increases capillary perfusion, deep venous flow velocity and return, improves lymphatic flow, cutaneous circulation, and muscle pump effectiveness, and decreases stasis and ambulatory venous pressures [60, 79].
The compression provided is generally divided into two categories: static and dynamic. Static compression characteristically involves the use of compression hosiery and bandages, and applies a constant pressure gradient along the affected extremity from distal to proximal. Certain pressures need to be achieved to therapeutically compress the superficial veins, and range from 20 to $25 \mathrm{mmHg}$ in supine patients and $35-40 \mathrm{mmHg}$ in upright patients [36]. Compression hosiery can be prescribed by any physician and vary in grade of compression, stocking length, and type of stocking depending on the extent of venous disease in the patient [80]. It is recommended that stockings be put on following placement of ulcer dressings in the morning when edema is minimal. Compression bandages are available as inelastic bandages or elastic compression systems and are applied by trained personnel. Multiple randomized controlled trials provide robust evidence for the benefits derived from the application of compression stockings with respect to the progression of CVI associated with edema and venous stasis ulcers [81-85]. Reduction of pain in these studies ranged widely from $12 \%$ to upwards of $50 \%$. Although Kinesio taping has been demonstrated to improve quality of life, gait outcome, and venous flow, its effect on pain seems to be mostly placebo-related and is inferior to conventional compression methods for pain relief $[86,87]$.

For patients with venous insufficiency refractory to static compression, dynamic compression therapy can be prescribed as an alternative. Devices with various options and a range of capabilities exist, but most fundamentally, dynamic compression involves the use of an electronic pneumatic compression pump that applies pressure intermittently by filling an inflatable garment worn around the arm or leg with compressed air [88]. More advanced multisegment compression devices are capable of exerting pressure sequentially in segments starting distally and moving proximally according to a user-defined program. This specifically imitates manual lymphatic drainage techniques to promote fluid clearance within the affected extremity [60]. 
Intermittent compression applied for $4 \mathrm{~h}$ /day has been demonstrated to provide a significant improvement in symptoms [89], though there is no clear protocol reported in literature. Pneumatic intermittent compression therapy is contraindicated in patients with significant arterial insufficiency, edema due to congestive heart failure, active phlebitis, DVT, or local wound infection.

Based upon systematic reviews and metaanalyses of controlled randomized trials, high pressure is more effective than low pressure, elastic multilayered compression is more effective than inelastic single-layer bandages, and external compression is more effective than no compression [90]. In general, compression therapy with stockings was found to produce either equivalent or better pain outcomes than compression bandages, with fewer complications [77, 84, 91-94] The efficacy of applying dynamic compression isolated of static compression is unclear, however. Thus, pneumatic compression is currently indicated and covered by Medicare and Medicaid only for patients with refractory edema with significant ulceration following 6 months of standard, static compressive therapies without sufficient improvement [88].

Compression is generally low risk, though a few complications associated with overcompression do exist. These include lower extremity ischemia, genital lymphedema, compartment syndrome, nerve compression, skin necrosis, fungal infection, and contact dermatitis, though most are predictable signs that can be avoided via patient education and removal or modification of the compressive force [60]. Despite evidence of a clear benefit and generally favorable safety outcomes, adherence to compression stocking usage unfortunately remains quite low, even among patients with significant pain. In one study, only $37 \%$ of patients with CVI, and $39 \%$ of patients with significant pain as a result thereof, reported continued use of compression stockings which were prescribed by a physician [95]. This proportion increased to $78 \%$ in a study of patients with leg ulcers [96]. Commonly cited reasons for nonadherence included discomfort and lack of apparent utility.

\section{Advances in Nonsurgical Management: Medical}

A number of medical agents have been used to supplement compression therapy and lifestyle changes in the treatment of CVI pain. These include venoactive agents (including flavonoids, sponins, calcium dobesilate, red vine leaf extract, etc.) and rheologic agents (including aspirin and pentoxifylline), which affect the venous tone and flow properties of blood, respectively.

Venoactive drugs are a heterogenous group of synthetic or natural plant flavonoid-derived agents. They have been shown to primarily increase venous tone through a noradrenalinemediated pathway, though more recent literature has shifted focus to the anti-inflammatory mechanisms [97]. Venoactive agents have also been demonstrated to reduce capillary permeability, improve lymphatic drainage, and decrease leukocyte adhesion and endothelial activation, all of which can treat pain via mediation against the pathophysiological mechanisms of CVI $[49,98,99]$. Many compounds have been trialed with varying success. Evidence of efficacy and any notable chemical properties, mechanisms of action, and side effects of some of the most commonly described venoactive agents are briefly reviewed below.

\section{Micronized Purified Flavonoid Fraction}

Micronized purified flavonoid fraction (MPFF) consists of a mixture of $90 \%$ micronized diosmin and $10 \%$ other active flavonoids. Research in a hamster model of venous stasis demonstrated that MPFF attenuated leukocyte-endothelial rolling and adherence, thus abrogating the inflammatory response to venous stasis. MPFF was found to be more effective than its component compounds individually, suggesting a synergistic effect between diosmin and other flavonoids [100, 101]. A large observational study and recent meta-analysis of double-blind, randomized, placebo-controlled trials of seven studies involving 1692 patients indicated that MPFF was highly effective in improving symptoms of leg pain, as well as 
other CVI-related symptoms including edema [102-105]. MPFF was also found to be effective for pain treatment in patients experiencing concomitant varicose veins in the pelvis and lower extremity [106]. Treatment with $1000 \mathrm{mg}$ once daily was not significantly worse than $500 \mathrm{mg}$ twice daily, which may improve patient adherence [107].

MPFF can also be used in combination with other conservative therapies. The VEIN ACT study was an international prospective study investigating the combination of MPFF, oral analgesics, and lower limb compression therapies. Subanalyses of the study in South American and Russian populations found that this regimen decreased pain by approximately 50\% $[108,109]$. Although this was not a randomized trial and did not compare treatment with and without MPFF, the results do suggest a role for MPFF therapy as part of multimodal conservative treatment for venous insufficiency symptoms. The combination of MPFF and compressive therapy improved ulcer healing and resolution of related pain, with the greatest impact on ulcers $\leq 10 \mathrm{~mm}$ [110]. A study comparing the efficacy of conventional therapy and adjunctive MPFF therapy on ulcer healing also demonstrated that MPFF supplementation increased the overall rate of ulcer healing at 6 months (61.3 vs. $47.6 \%)$ and decreased time to healing (16 vs. 21 weeks) [111]. For patients who undergo venous procedures, MPFF has been shown to decrease symptoms when given preoperatively and in the days after the procedure [112-114]. The safety of MPFF during pregnancy has not yet been established, and in clinical trials, MPFF had a tolerability profile similar to that of administered placebos [115].

\section{Horse Chestnut Seed Extract}

Horse chestnut seed extract (HCSE) is a naturally derived agent that contains the active ingredient escin, a triterpenic saponin. The proposed mechanism of action of escin is multifold. It has been shown to reduce vascular edema through "sealing" of vessel walls by increasing calcium sensitivity in vascular smooth muscle and inhibiting enzymes responsible for degrading the extracellular matrix [116-118]. Similarly, reduced capillary permeability contributes to the anti-inflammatory effects of escin, along with a possible action on glucocorticoid receptors resulting in decreased inflammatory factors such as nuclear factor (NF)- $\kappa \mathrm{B}$, tumor necrosis factor alpha (TNF- $\alpha$ ), and interleukin $1 \beta[86,118-120]$. Escin also exerts a venotonic effect, increasing venous smooth tissue tone and stimulating contraction [121]. Several placebo-controlled trials and meta-analyses of patients taking oral horse chestnut seed extract have reported statistically significant improvement in leg pain and edema when compared to placebo or baseline [102, 111, 117, 122, 123]. Eight studies reported adverse side effects in patients taking HCSE including gastrointestinal tract symptoms, dizziness, nausea, headache, and pruritus, though the reported frequencies were low $(0.9-3.0 \%)$, and the frequency was not significantly different from that of placebos in three studies [122]. There was also one case report of pericardial effusion leading to tamponade as a result of the use of horse chestnut paste [124]. Three hundred milligrams of HCSE (equivalent to $50 \mathrm{mg}$ of escin) taken twice daily for 12 weeks yielded therapeutic effects comparable to compression therapy with regard to edema reduction and can be recommended for patients who cannot otherwise benefit from compressive therapy [122].

\section{Calcium Dobesilate}

Calcium dobesilate (2,5-dihydroxy-benzenesulfonate) is a synthetic drug with well-established pharmacologic properties and demonstrated beneficial therapeutic effects in treatment of CVI [49, 103]. In vitro experiments have demonstrated a protective effect against both inflammation and oxidative stress [125]. Results of clinical trials of calcium dobesilate have been mixed. Three randomized trials enrolling a total of more than 600 patients found a statistically significant benefit in lower leg pain, as well as a significant decrease in lower extremity circumference, after 7-12 weeks of treatment [126-128]. However, a systematic review 
demonstrated no overall benefit on lower extremity pain, although a benefit was seen in night cramps and discomfort [129]. A recent randomized, parallel, double-blind, placebocontrolled clinical trial with over $500 \mathrm{CVI}$ patients revealed that 3 months of calcium dobesilate treatment resulted in no significant improvements in CVI symptoms, including pain, compared to placebo [130]. Differences between studies and evaluation of subjective outcomes such as pain are a source of heterogeneity. It is hypothesized that calcium dobesilate has higher efficacy in patients with more severe forms of CVI, as they can benefit from a synthetic drug with a precise chemical structure which blocks many specific pathophysiological pathways of the disease [129]. A Cochrane review demonstrated no difference in quality of life for calcium dobesilate versus placebo [131]. Usage of calcium dobesilate has been associated with some cases of transient agranulocytosis [103].

\section{Red Vine Leaf Extract}

Red vine leaf extract is a herbal medicine containing several flavonoids including quercetin3-O-beta-glucuronide and isoquercitrin (quercetin-3-O-beta-glycoside). Red vine leaf extracts have demonstrated strong anti-inflammatory and anti-oxidant properties, leading to downregulation of inflammatory regulators, elimination of reactive oxygen species, and protection of the vascular endothelium [132-134]. Human studies showed that these compounds almost doubled microvascular blood flow velocity compared to placebo following a 6-week treatment period, possibly through induction of nitric oxide synthase $[132,133,135]$. An observational clinical trial reported a decrease in feelings of pain and heaviness after 6 weeks of red vine extract treatment [136]. Three randomized placebo-controlled trials all demonstrated decreased lower extremity volume and significantly lower pain levels in patients treated with red vine extract when compared to placebo [137-139]. Tolerability was reported as good or satisfactory and occurred at similar rates as placebo, with common adverse effects including gastrointestinal distress, hypercholesterolemia, dizziness, malaise, urticaria, and sleep disturbance. Further high-quality trials are needed for more conclusive evidence [140].

\section{Pentoxifylline}

Pentoxifylline is a drug indicated specifically for the management of venous leg ulcers. However, similarly to the other drugs mentioned above, the mechanism of action of pentoxifylline is likely related to an anti-inflammatory effect including downregulation of cellular adhesion molecules and TNF- $\alpha$, as well as free radical neutralization [141, 142]. A review of 12 clinical trials demonstrated improved ulcer healing with pentoxifylline therapy alone and when used to supplement compression compared to placebo [143-146]. Unfortunately, most of these studies did not include pain as a measured outcome. A later randomized trial found increased ulcer healing in patients treated with pentoxifylline and compression versus compression alone; however, pain outcomes were not significantly different between groups [147]. Patients given a standard dose of pentoxifylline three times a day demonstrated faster ulcer healing than those receiving placebo, with a higher dose $(800 \mathrm{mg})$ being more effective than the lower dose $(400 \mathrm{mg})$. Beneficial effects for pentoxifylline were also observed in the absence of simultaneous compression therapy, indicating a role in treatment of patients who are unable to tolerate compression [148]. Pentoxifylline use is commonly associated with gastrointestinal side effects [111].

The literature describes minimal safety concerns with the use of these drugs and no increased risk of adverse pregnancy outcome among women exposed to examined vasoactive agents [103, 115, 149]. Given the relative safety and small-scale evidence of their efficacy in relieving CVI-related symptoms, vasoactive agents have been formally designated with weak recommendation for the management of CVI in the latest edition of the Handbook of Venous Disorders [103]. Current clinical practice guidelines suggest the use of venoactive drugs 
including flavonoids, MPFF, and horse chestnut seed extract to relieve general pain and swelling, and pentoxifylline (400 mg orally, 3 times a day) or MPFF supplemented with compression to accelerate venous ulcer healing [39].

\section{ADVANCES IN SURGICAL MANAGEMENT}

Invasive therapy to treat chronic lower extremity venous disease accounted for over $\$ 290$ million in Medicare expenditure in 2019. Historically, the first known surgical intervention for the treatment of lower extremity chronic venous disease (LECVD) was when the French surgeon Pravaz designed the syringe and needle technique for vascular injection in 1831 [150]. Within the last century, surgical application in managing this condition has witnessed an evolution from the previously discredited sclerotherapy for varicose veins through to bypass procedures to valve reconstruction.

\section{Saphenous/Saphenofemoral Vein Ligation and Stripping}

Saphenous/saphenofemoral vein ligation and stripping involves the removal of the varicose vein from the leg. In about $20 \%$ of limbs with varicose veins, there is a deep venous reflux that accompanies the superficial venous reflux, usually around the saphenofemoral junction and mid-thigh Hunterian, making the targeting of this circuit for removal crucial in management. This procedure is usually performed under general or spinal anesthesia, with the great saphenous vein pulled or "stripped" from under the skin. Vein stripping has been shown to be an effective treatment for venous insufficiency, with one study demonstrating recurrence of varicose veins in only $3 \%$ of patients and no recurrence of pain symptoms [151]. A randomized trial comparing vein stripping to conservative treatment found marked improvement in aching symptoms in patients treated surgically (80\% improvement vs. $26 \%$ with conservative treatment). Quality of life at 1 and 2 years postenrollment was also significantly higher in the surgical group [152]. Two clinical trials have failed to demonstrate improved pain outcomes in patients undergoing vein stripping who were treated with leg compression in the immediate postoperative period $[153,154]$.

\section{Subfascial Endoscopic Perforator Surgery}

G. Hauer, a German surgeon, first described the subfascial endoscopic perforator surgery (SEPS) technique in 1985, with several ensuing modifications. The goal usually is to find and ligate perforating veins and is used to treat CVI. SEPS provides the means to avoid incisions in unhealthy areas of the skin and enables access to a higher number of perforators. Patients undergoing SEPS were shown to exhibit earlier relief of symptoms and better ulcer healing [150]. Treatment with SEPS in combination with venous stripping was found in one study to significantly decrease pain scores postoperatively; however, no difference was found in pain scores when compared to stripping alone without SEPS [155]. Unfortunately, a Cochrane review determined that most comparative studies of SEPS did not investigate pain as a study outcome, and no overall conclusion could be drawn [156].

\section{Phlebectomy}

Phlebectomy (also known as microphlebectomy or stab avulsion) is used to target bulging varicose veins closer to the surface of the skin. This technique is highly recommended for tortuous distal varicosities and offers improved cosmetic results and decreased risk of blood clots [157]. Phlebectomy may be performed via a conventional multiple stab technique; recently, however, transilluminated powered phlebectomy (TIPP), in which transillumination is used to guide mechanical vein avulsion following hydrodissection using tumescent anesthesia, has gained popularity due to its minimally invasive nature and ease of use. TIPP has been shown to reduce pain associated with venous insufficiency, although two clinical trials failed to demonstrate improvement in pain relief when compared to traditional phlebectomy, 
and in one trial in fact resulted in increased pain at 6-week postoperative follow-up [158-163]. Phlebectomy has also been used as a concomitant adjunct procedure during endovenous laser therapy (EVLT; see below). Comparisons of EVLT with and without phlebectomy have demonstrated superior symptom scores, including pain, in patients treated with EVLT and phlebectomy [164-166]. Several studies have also suggested that simultaneous phlebectomy reduces the need for additional procedures following EVLT, although one recent retrospective study failed to demonstrate such a difference and was used to support the study group's assertion that phlebectomy is unnecessary at the time of EVLT [166, 167].

\section{Hemodynamic Correction Procedure (CHIVA)}

The hemodynamic correction procedure (CHIVA) is a minimally invasive treatment approach with the use of ultrasound. This technique uses local anesthetics and targets the mid-thigh Hunterian or saphenopopliteal junction in order to decrease the hydrostatic pressure exerted by the deep venous and superficial venous refluxes within that area. The risk of recurrence in patients undergoing this procedure was significantly lower when compared with vein stripping $[43,168,169]$. Additionally, this study found that the technique was associated with greater reduction in pain while avoiding nerve damage. Clinical outcomes, including pain, in patients undergoing CHIVA were observed to be superior to vein stripping in two randomized trials and one retrospective review, but were not statistically significantly different in two other randomized trials [168, 170-173]. A prospective observational trial comparing CHIVA to vein stripping and endovenous laser ablation found total resolution of pain in patients treated with CHIVA after 1 year; although all three treatments had very good pain outcomes, the cost of CHIVA was found to be only one-fifth of the laser ablation cost [174]. Potential drawbacks of CHIVA include a steep learning curve and high rates of superficial thrombophlebitis in surgeons with limited experience in the technique $[175,176]$.

\section{ADVANCES IN MINIMALLY INVASIVE TREATMENT}

\section{Endovenous Thermal Ablation (EVTA)}

\section{Endovenous Laser Ablation (EVLA)}

This procedure can be used to improve quality of life, address skin color changes, and perform cosmetic restorations. A thorough history and physical with ultrasound imaging is a prerequisite to find qualifying patients. Tumescent anesthetic is used here to access perivenous spaces while limiting this access to local areas. Lidocaine with or without epinephrine in normal saline with a sodium bicarbonate buffer solution is appropriate. The United States Food and Drug Administration (FDA) recommends a maximum dose of $5 \mathrm{mg} / \mathrm{kg}$ of lidocaine without epinephrine and $7 \mathrm{mg} / \mathrm{kg}$ with epinephrine.

In 2018, a comparison study evaluating outcomes of laser ablation and surgery found worse bruising and swelling with surgery, while similar pain levels were experienced at the onset of each procedure [177]. In comparison to surgery and ultrasound-guided foam sclerotherapy (UGFS), a meta-analysis suggests that endovenous treatments of lower extremity varicosities are better in achieving anatomic success such as obliteration or disappearance of veins. Of the endovenous therapies, EVLA is significantly more effective than radio-frequency ablation (RFA) to obliterate insufficient veins [178].

In terms of pain outcomes, EVLA has proven to be effective in treating symptoms of venous insufficiency. Most clinical trials evaluating EVLA used composite scoring systems such as the Venous Clinical Severity Score (VCSS), Aberdeen Varicose Vein Questionnaire (AVVQ), or Chronic Venous Insufficiency Quality of Life Questionnaire (CIVIQ), all of which include pain, to evaluate overall symptomatic improvement [179]. EVLA is effective for reducing symptoms due to CVI $[179,180]$.

In comparison with other treatment methods, no significant difference in symptomatic outcomes was observed comparing EVLA to 
open surgery in several randomized trials, as both therapies were found to be equally effective and had high patient satisfaction [181-184]. However, EVLA was found to be advantageous compared to surgery due to quicker recovery, lower complication rate, and lower cost [181, 183, 184]. Comparison of EVLA to more advanced minimally invasive techniques will be further described in those respective sections (Table 2 ).

EVLA is generally safe, with a low rate of complications. Common adverse outcomes include postoperative pain, paresthesia, thrombophlebitis, edema, skin changes, and hematoma $[179,185]$. Creation of DVT due to heating of tissue is a feared complication, but is rare [185].

\section{Radio-frequency Ablation (RFA)}

The radio-frequency ablation technique was first introduced in the 1990s and has been used to treat other conditions since then. It can also be applied directly or indirectly, with the first indirect method used in 1999. A radio-frequency catheter, usually about $65-100 \mathrm{~cm}$ long, is introduced into the leg with a 7 French sheath, while puncturing of the target vein allows for anesthesia input which in this case is tumescent in nature. Venous filling index measurements have shown that RFA leads to clinically apparent improvement in venous reflux as early as 1 week postoperatively [186].

The EVOLVEeS trial showed a significant sonographically determined improvement in anatomy for radio-frequency when compared with surgical stripping [187]. This study also demonstrated a higher rate of closure and improved quality of life scores when participants were observed for 2 years. On the other hand, a subgroup meta-analysis by Bos et al. in 2009 showed no significant differences in effectiveness between RFA and stripping [178]. Similarly, several other clinical trials evaluating RFA versus stripping surgery demonstrated improvement in clinical symptom indices without significant differences between treatment arms [188-192]. As with EVLA, RFA was found to result in lower immediate postoperative pain, lower complication rate, and decreased hospital length of stay [193]. Patient satisfaction was increased after RFA compared to surgical stripping [189].

In comparison with EVLA, RFA has been shown in the majority of studies to have no significant difference in quality of life or symptomatic outcomes; however, two prospective studies showed improved pain outcomes in EVLA [179, 194-203]. Conversely, analgesic requirement, bruising, and discomfort in the immediate postoperative period were lower in patients who underwent RFA [197, 198]. It was also further highlighted that EVLA and RFA have the same occlusion rates, but patients treated with RFA have less postoperative pain, faster recovery, and less bruising [150, 194, 195]. In another study, RFA was demonstrated to have lower rates of complications than EVLA; however, a retrospective study of over 10,000 endovenous ablation procedures found an increased rate of heat-induced thrombosis in RFA versus EVLA [196, 203]. Clinical recurrence rates were improved in RFA compared to venous stripping and EVLA in one clinical trial, although a definitive explanation still remains to be found [204].

\section{Endovenous Non-thermal Ablation}

\section{Microfoam Sclerotherapy or Ultrasound Foam Sclerotherapy (USFS)}

Chemical agents such as polidocanol, sodium tetradecyl sulphate (STS), morrhuate sodium, glycerin, and hypertonic saline are injected into the vessel either as pure agents or in the form of foam in order to damage and denude the vessel endothelium. The amount of agent used increases with the size of the vessel [150]. Sclerosant foam was developed to increase the surface area of exposure and is very useful, as its echogenic texture allows for easier visualization with duplex ultrasound [205]. It is used for larger $(>6 \mathrm{~mm})$ varicose veins and refluxing axial veins. Candidates for this procedure are those for which there are persistent symptoms with chronic disease and treatment resistance. Its usage is applied for the treatment of reflux in perforator veins, and great, small, and accessory saphenous veins due to its ability to treat tributary veins. Fegan's technique of low- 
compression sclerotherapy was found to be effective in treating bleeding varicose veins, with no recurrence 12 months later [206].

Across several clinical trials, pain outcomes with foam therapy generally resulted in improved quality of life and decreased pain scores. However, there is little evidence from randomized trials to suggest that foam therapy pain outcomes are significantly different from surgical stripping [192, 194, 195, 207-212].

Compared to EVLA, however, pain outcomes are more mixed between trials. Several trials have found no significant difference in symptom questionnaire scores between EVLA and foam therapy [195, 207, 213]. Comparisons from other trials reflect less favorably on foam therapy. Foam therapy was found to have poorer CIVIQ symptom outcomes after 5 years in one randomized trial [211]. Another study determined that long-term cost-effectiveness of foam therapy was inferior to EVLA, and EVLA was suggested over both foam and surgery for suitable patients [181, 214]. Foam therapy had a higher occlusive failure rate when compared to RFA, EVLA, and stripping, although recovery time, postoperative pain, and total surgical cost were lower when compared to EVLA and stripping [194, 195, 209, 215, 216]. As a result, the risk for reoperation may be higher following foam sclerotherapy, thus obviating some of its initial economic advantages over other treatment modalities.

Adverse effects following foam sclerotherapy commonly include phlebitis, hyperpigmentation, and telangiectatic matting. More serious events include DVT and stroke, both of which are rare, and are decreased in incidence compared to surgery and RFA; however, episodes of transient visual disturbance following sclerotherapy may be seen in up to $2 \%$ of cases [217-219].

\section{Liquid Sclerotherapy}

This is the gold standard for treating lower extremity telangiectasia and reticular veins. It is used for small nonaxial veins, in comparison to foam sclerotherapy, which is better suited for large varicose veins. In particular, patients with Fitzpatrick skin types IV, V, or VI are best treated with liquid sclerotherapy, as it has a much lower risk of hypopigmentation that is common with other treatments [99].

In recent years, several clinical trials have demonstrated decreased efficacy of liquid sclerotherapy when compared to foam for treatment of saphenous vein varicosities. A metaanalysis and a systematic review both demonstrated increased efficacy when evaluating ultrasound-demonstrated elimination of reflux [220, 221].

One trial measuring VCSS scores at 1 month postoperatively demonstrated significantly decreased pain in both liquid and foam sclerotherapy, with no statistically significant difference between modalities [222]. Pain was also reduced at 15 days and 30 days postoperatively in two other controlled trials, although this difference was not statistically significant at 90 days [223, 224]. However, another trial measuring outcomes at 3 months determined that although mean changes in CIVIQ scores were comparable between groups, patient and physician satisfaction with foam sclerotherapy was significantly higher [225]. Liquid therapy was noted to have overall similar or perhaps fewer complications, although both therapies were determined to be generally safe [221, 226-228]. Adverse events in liquid sclerotherapy were similar to those of foam sclerotherapy. Although pain outcomes may be improved in liquid sclerotherapy compared to foam treatment, the overall balance of outcomes seems to favor foam sclerotherapy for definitive treatment of venous insufficiency.

\section{Cyanoacrylate Embolization (CAE)}

In 2013, the first human use of cyanoacrylate adhesive for treatment of great saphenous vein incompetence was reported [229]. Venous injection of cyanoacrylate adhesive forms a glue plug that occludes the insufficient vein. The results demonstrated a $92 \%$ closure at follow-up 12 months later and mild self-limiting side effects. Anesthesia is not required when cyanoacrylate glue in microbead form is injected in a small volume (about $0.3 \mathrm{ml}$ ) into the distal part of the saphenofemoral junction. Subsequent studies have demonstrated promising outcomes for patients treated with CAE, especially with regard to symptomatic 
improvement. VCSS scores were improved by $>50 \%$, with continued favorable safety profiles [230-232].

Comparison studies of CAE with established therapies for venous insufficiency are ongoing. In a randomized controlled trial, Morrison et al. compared cyanoacrylate embolization and RFA for incompetent great saphenous vein treatment. The short-term outcome was similar at 3-month follow-up, and both treatment methods showed good safety profiles and pain profiles [233]. Subsequent trials comparing CAE and RFA also demonstrated similar rates of treatment success as measured by adequate venous occlusion, with one study also showing similar VCSS scores between treatment groups [232, 234, 235]. However, a recently published study cast doubt on this equivalency by showing inferior results for CAE on VCSS, SF-36, and CIVIQ-14 questionnaires when compared to surgery and RFA [236]. Advantages associated with CAE compared to RFA include decreased postoperative complications, as well as decreased pain at 12-month follow-up [232, 234, 235]. EVLA was found to be similar to CAE in VCSS symptom improvement, but CAE demonstrated a lower rate of treatment complications [237, 238]. Common complications after CAE included thrombophlebitis, postoperative pain, and superficial vein thrombosis [239]. Because experimental evidence demonstrates a possible resorption of glue over time, further follow-up of sustained pain improvement must be pursued before CAE can be definitively recommended as a first-line therapy. [240, 241].

Combination Techniques (Mechanochemical Ablation) Mechanochemical ablation (aka ClariVein or MOCA) is a technique first introduced in the United States in 2008. Useful in treating saphenous veins, this technique is similar to thermal ablation except that heat is not used. A wire is used to pierce the vein (or create a canal) in the knee or ankle at a proximal position, while a sclerosant is introduced distally. In the case of the saphenous vein, this wire introduction is activated at the saphenofemoral junction using either polidocanol or sodium tetradecyl sulfate sclerosing agents [242].

In a randomized controlled trial in patients with symptomatic, unilateral, single-axis (great saphenous vein, anterior accessory saphenous vein, or small saphenous vein) primary unilateral symptomatic superficial venous incompetence (SVI), it was concluded that EVLA resulted in a higher technical success rate compared to MOCA [243]. Clinically, both EVLA and MOCA were highly efficacious in the treatment of SVI, thus showing a significant improvement in VCSS and patient symptoms as reflected in the improved generic and disease-specific quality of life of the patients. Multiple randomized trials have shown that symptomatic outcomes are comparable or even superior in MOCA to patients receiving EVLA or RFA, with increased speed of improvement in VCSS scores following MOCA [243-247]. Furthermore, it was observed that the procedural discomfort from MOCA was as low as or lower than EVLA and that the postprocedure pain from MOCA during the first week tended to be lower [243, 247]. MOCA patients also had lower rates of postoperative phlebitis and returned to work earlier than EVLA patients [245].

MOCA has been demonstrated to be a safe intervention, in part due to its lack of need for thermal ablation. As a result, paresthesia due to peripheral nerve damage is much less common compared to RFA and EVLA [248]. Complications commonly associated with MOCA include thrombophlebitis, hyperpigmentation, skin induration, and local hematoma [249-252]. Unfortunately, DVT and subsequent pulmonary embolism have been reported as rare but serious complications and deserve consideration going forward [252, 253].

It is suggested that within a year, MOCA is as effective as EVLA in treating single-axis reflux SVI; however, higher recanalization rates after MOCA may lead to higher rates of recurrence in the long term [243]. This result is supported by multiple clinical trials demonstrating decreased occlusion of the great saphenous vein 1 year after treatment in MOCA patients versus patients who underwent EVLA or RFA [243, 244]. Initial clinical follow-up results demonstrated that symptomatic benefits are 
Table 2 Efficacy of noninvasive surgery relative to invasive surgery or other procedures

\begin{tabular}{ll}
\hline Treatment & Efficacy in comparison to invasive surgery or other procedures \\
\hline $\begin{array}{l}\text { Endovenous thermal } \\
\text { ablation }\end{array}$ \\
$\begin{array}{l}\text { Endovenous laser ablation } \\
\text { (EVLA) }\end{array}$ \\
$\begin{array}{l}\text { When compared with surgery there is less postoperative pain and bruising [150] } \\
\text { A subgroup meta-analysis of } 58 \text { prospective studies confirmed that EVLA was significantly } \\
(p=0.01)[178]\end{array}$
\end{tabular}

At 1 year after procedure, occlusion rates of EVLA vary between 77 and 99\%, suggesting no significant difference in varicose vein recurrence when compared with surgery (HL or stripping) [150]

Radio-frequency ablation (RFA)

Subgroup meta-analysis showed no significant differences in effectiveness for RFA vs. stripping $(p=0.14)$ and RFA vs. UGFS $(p=0.13)$ [175]. It was also further highlighted that EVLA and RFA have the same occlusion rates, but patients treated with RFA have less postoperative pain and bruising [150]

Endovenous non-thermal ablation

Foam sclerotherapy (USFS) When compared with surgery, although USFS has been suggested to be less efficient in multiple studies, it has significantly fewer side effects (less pain, better postoperative quality of life, faster return to normal activities) and is a less time-consuming treatment that can be easily repeated [150]

After 6 years, the varicose vein recurrence after USFS is as high as $90 \%$. In comparison to surgery, the need for additional treatment creates more major problems with the treatment [150]

Cyanoacrylate embolization In a randomized controlled trial by Morrison et al. comparing cyanoacrylate embolization (CAE) and RFA for incompetent great saphenous vein treatment, the short-term outcome was similar at 3-month follow-up, and both treatment methods showed good safety profiles and pain profiles. In the study, CAE was also associated with less post-procedure ecchymosis [233]

Mechanochemical ablation The procedural discomfort from MOCA is similar to EVLA; however, the post-procedure (MOCA) pain from MOCA during the first week tends to be lower than EVLA. MOCA also showed similar improvements in generic and disease-specific quality of life in patients [243]

preserved at 1 year postoperatively; however, some studies have demonstrated deterioration in VCSS and overall quality of life scores at 1 to 3 years, although they remained improved relative to baseline [250, 253-255]. Thus, questions still remain about the long-term viability of this intervention.

\section{Management Overview}

Management of pain in symptomatic CVI is complex and varies according to disease severity as well as the mechanism of the underlaying disease. The following is a guiding algorithm for CVI management that summarizes the medical and surgical modalities described above. 
Initial treatment that should be recommended for all patients with symptoms and signs of CVI includes passive leg elevation, exercise, and compression therapy as described earlier. These conservative measures enhance the normal venous flow, conferring physiologic benefits by improving oxygen transport to the tissues, decreasing edema, and reducing inflammation. These treatments should not be considered in isolation but rather supplementary to each other, and more aggressive initial treatment may be considered in the presence of complications including thrombosis, bleeding, or ulceration. Specifically, if ulceration is present, aspirin should be administered and a clinical infection should be suspected and treated appropriately following confirmation via culture.

Pharmacologic therapy (venoactive and rheologic agents) may be added to the management regimen if the patient has painful edema and ulcers resistant to initial conservative treatment. These are systemic agents that artificially affect venous tone and blood flow properties to treat the signs and symptoms of CVI.

Patients with severe, refractory CVI should undergo venous duplex ultrasound to confirm the diagnosis with demonstration of reflux and to identify specific segments of venous incompetence before undergoing surgical treatment. These modalities directly therapeutically target areas of venous incompetence and include venous ablation, vein stripping, and ultrasound-guided foam sclerotherapy, among others previously described above.

\section{CONCLUSION}

CVI is widespread, multifaceted, and associated with high levels of morbidity in sufferers. Pain, a common presenting symptom of CVI, makes up a large portion of that morbidity and remains an under-investigated manifestation of an under-investigated disease. Although the mainstay of initial treatment for CVI-associated pain remains conservative management and lifestyle modification, medical therapy can be an effective adjunct in patients for whom conservative management has failed. Both vasoactive and rheologic pharmacologic agents present a favorable safety profile across patient populations. Recent strides in minimally invasive surgical management of venous insufficiency have offered improvements in comfort and postoperative recovery in comparison to open surgery, although long-term outcomes of these approaches in providing patients permanent relief from CVI-associated pain must still be further elucidated. Individual counseling and patient-oriented discussion should be pursued when deciding which therapies are appropriate to pursue.

\section{ACKNOWLEDGEMENTS}

Funding. No Rapid Service Fee was received by the journal for the publication of this article.

Authorship. All named authors meet the International Committee of Medical Journal Editors (ICMJE) criteria for authorship for this article, take responsibility for the integrity of the work as a whole, and have given their approval for this version to be published.

Disclosures. Vwaire Orhurhu, Robert Chu, Katherine Xie, Ghislain N Kamanyi, Bisola Salisu, Mariam Salisu, Ivan Urits, Rachel J. Kaye, Jamal Hasoon, Omar Viswanath, Aaron J. Kaye, Jay Karri, Zwade Marshall, Alan D. Kaye, and Dua Anahita have nothing to disclose.

Compliance with ethics guidelines. This review article is a de-identified overview that contains factual information. This article is based on previously conducted studies and does not contain any new studies with human participants or animals performed by any of the authors. The review article does not require institutional review board (IRB) approval or exempt determination. This review article does not directly involve "human subjects" as defined by federal regulations and guidance (https://www.hhs.gov/ohrp/regulations-andpolicy/regulations/common-rule/index.html). Thus, all procedures performed were in 
accordance with the ethical standards of the institutional and/or national research committee and with the 1964 Helsinki declaration and its later amendments or comparable ethical standards.

Data availability. Data sharing is not applicable to this article as no data sets were generated or analyzed during the current study.

Open Access. This article is licensed under a Creative Commons Attribution-NonCommercial 4.0 International License, which permits any non-commercial use, sharing, adaptation, distribution and reproduction in any medium or format, as long as you give appropriate credit to the original author(s) and the source, provide a link to the Creative Commons licence, and indicate if changes were made. The images or other third party material in this article are included in the article's Creative Commons licence, unless indicated otherwise in a credit line to the material. If material is not included in the article's Creative Commons licence and your intended use is not permitted by statutory regulation or exceeds the permitted use, you will need to obtain permission directly from the copyright holder. To view a copy of this licence, visit http://creativecommons.org/licenses/by$\mathrm{nc} / 4.0 /$.

\section{REFERENCES}

1. Beebe-Dimmer JL, et al. The epidemiology of chronic venous insufficiency and varicose veins. Ann Epidemiol. 2005;15(3):175-84.

2. Evans CJ, et al. Prevalence of varicose veins and chronic venous insufficiency in men and women in the general population: Edinburgh Vein Study. J Epidemiol Commun H. 1999;53(3):149-53.

3. Criqui $\mathrm{MH}$, et al. Chronic venous disease in an ethnically diverse population: the San Diego Population Study. Am J Epidemiol. 2003;158(5):448-56.

4. Eberth-Willershausen W, Marshall M. Prevalence, risk factors and complications of peripheral venous diseases in the Munich population. Hautarzt. 1984;35(2):68-77.
5. Adhikari A, et al. The epidemiology of chronic venous diseases. Phlebolymphology. 2004;47: 299-303.

6. Criqui $\mathrm{MH}$, et al. Risk factors for chronic venous disease: the San Diego Population Study. J Vasc Surg. 2007;46(2):331-7.

7. Brand FN, et al. The epidemiology of varicose veins: the Framingham Study. Am J Prev Med. 1988;4(2): 96-101.

8. Raetz J, Wilson M, Collins K. Varicose veins: diagnosis and treatment. Am Fam Physician. 2019;99(11):682-8.

9. Boccalon $\mathrm{H}$, et al. Characteristics of chronic venous insufficiency in 895 patients followed in general practice. Int Angiol. 1997;16(4):226-34.

10. Maffei FHA, et al. Varicose veins and chronic venous insufficiency in Brazil: prevalence among 1755 inhabitants of a country town. Int J Epidemiol. 1986;15(2):210-7.

11. Rabe E, et al. Bonner venenstudie der deutschen gesellschaft für phlebologie. Phlebologie. 2003;32(01):1-14.

12. Vuylsteke ME, et al. The influence of age and gender on venous symptomatology. An epidemiological survey in Belgium and Luxembourg. Phlebology. 2016;31(5):325-33.

13. Criqui $\mathrm{MH}$, et al. Epidemiology of chronic peripheral venous disease. In: The vein book. Amsterdam: Elsevier; 2007. p. 27-37.

14. Bonkemeyer Millan S, Gan R, Townsend PE. Venous ulcers: diagnosis and treatment. Am Fam Physician. 2019;100(5):298-305.

15. Mekky S, Schilling RSF, Walford J. Varicose veins in women cotton workers. An epidemiological study in England and Egypt. Br Med J. 1969;2(5657): 591-5.

16. Zolotukhin IA, et al. Prevalence and risk factors for chronic venous disease in the general Russian population. Eur J Vasc Endovasc Surg. 2017;54(6): 752-8.

17. Dindelli $M$, et al. Risk factors for varicose disease before and during pregnancy. Angiology. 1993;44(5):361-7.

18. Gourgou S, Dedieu F, Sancho-Garnier H. Lower limb venous insufficiency and tobacco smoking: a casecontrol study. Am J Epidemiol. 2002;155(11): 1007-15. 
19. Abramson JH, Hopp C, Epstein LM. The epidemiology of varicose veins. A survey in western Jerusalem. J Epidemiol Commun H. 1981;35(3):213-7.

20. Labropoulos N, Delis KT, Nicolaides AN. Venous reflux in symptom-free vascular surgeons. J Vasc Surg. 1995;22(2):150-4.

21. Tüchsen F, et al. Prolonged standing at work and hospitalisation due to varicose veins: a 12 year prospective study of the Danish population. Occup Environ Med. 2005;62(12):847-50.

22. Lee AJ, et al. Pregnancy, oral contraception, hormone replacement therapy and the occurrence of varicose veins: Edinburgh vein study. Phlebology. 1999;14(3):111-7.

23. Eberhardt RT, Raffetto JD. Chronic venous insufficiency. Circulation. 2014;130(4):333-46.

24. Meissner $\mathrm{MH}$, et al. The hemodynamics and diagnosis of venous disease. J Vasc Surg. 2007;46(6): S4-24.

25. Labropoulos $\mathrm{N}$, et al. Where does venous reflux start? J Vasc Surg. 1997;26(5):736-42.

26. Crawford JM, et al. Pathophysiology of venous ulceration. J Vasc Surg Venous Lymphat Disord. 2017;5(4):596-605.

27. Miteva M, Romanelli P, Kirsner RS. Lipodermatosclerosis. Derm Ther. 2010;23(4):375-88.

28. Grosse SD, Nelson RE, Nyarko KA, Richardson LC, Raskob GE. The economic burden of incident venous thromboembolism in the United States: a review of estimated attributable healthcare costs. Thromb Res. 2016;137:3-10.

29. Kahn SR. The post-thrombotic syndrome. Hematology Am Soc Hematol Educ Program. 2016;2016(1):413-8.

30. Di Nisio M, van Es N, Büller HR. Deep vein thrombosis and pulmonary embolism. Lancet. 2016;388(10063):3060-73.

31. Santler B, Goerge T. Chronic venous insufficiencya review of pathophysiology, diagnosis, and treatment. J Dtsch Dermatol Ges. 2017;15(5):538-56.

32. Bergan JJ, et al. Chronic venous disease. N Engl J Med. 2006;355(5):488-98.

33. Carpentier $\mathrm{PH}$, et al. Appraisal of the information content of the C classes of CEAP clinical classification of chronic venous disorders: a multicenter evaluation of 872 patients. J Vasc Surg. 2003;37(4): 827-33.
34. Lee AJ, et al. Progression of varicose veins and chronic venous insufficiency in the general population in the Edinburgh Vein Study. J Vasc Surg Venous Lymphat Disord. 2015;3(1):18-26.

35. Kaplan RM, et al. Quality of life in patients with chronic venous disease: San Diego population study. J Vasc Surg. 2003;37(5):1047-53.

36. Green J, et al. The impact of chronic venous leg ulcers: a systematic review. J Wound Care. 2014;23(12):601-12.

37. Ruckley CV. Socioeconomic impact of chronic venous insufficiency and leg ulcers. Angiology. 1997;48(1):67-9.

38. Van den Oever R, et al. Socio-economic impact of chronic venous insufficiency. An underestimated public health problem. Int Angiol. 1998;17(3): $161-7$.

39. Young YJ, Lee J. Chronic venous insufficiency and varicose veins of the lower extremities. Korean J Intern Med. 2019;34(2):269-83.

40. Lurie F, Passman M, Meisner M, Dalsing M, Masuda E, Welch H, Bush RL, Blebea J, Carpentier PH, De Maeseneer M, Gasparis A, Labropoulos N, Marston WA, Raffeto J, Santiago F, Shortell C, Uhl JF, Urbanek T, van Rij A, Eklof B, Gloviczki P, Kistner R, Lawrence P, Moneta G, Padberg F, Perrin M, Wakefield T. The 2020 update of the CEAP classification system and reporting standards. J Vasc Surg Venous Lymphat Disord. 2020;8(3):342-52.

41. Burrus MT, et al. Chronic leg pain in athletes. Am J Sport Med. 2015;43(6):1538-47.

42. Branisteanu DE, et al. Impact of chronic venous disease on quality of life: results of vein alarm study. Exp Ther Med. 2019;17(2):1091-6.

43. Escudero Rodríguez JR, Fernández Quesada F, Bellmunt Montoya S. Prevalence and clinical characteristics of chronic venous disease in patients seen in primary care in Spain: results of the international study vein consult program. Cir Espan. 2014;92(8): 539-46.

44. Aguilar-Ferrándiz ME, et al. Evaluation of pain associated with chronic venous insufficiency in Spanish postmenopausal women. Menopause. 2015;22(1):88-95.

45. Andreozzi G, et al. Quality of life in chronic venous insufficiency. Int Angiol. 2005;24(3):272e7.

46. Arndt J, Klement W. Pain evoked by polymodal stimulation of hand veins in humans. J Physiol. 1991;440(1):467-78. 
47. Danziger N. Physiopathologie de la douleur au cours de la maladie veineuse. J Mal Vascul. 2007;32(1):1-7.

48. Lim RKS, et al. Visceral receptors concerned in visceral pain and the pseudaffective response to intraarterial injection of bradykinin and other algesic agents. J Comp Neurol. 1962;118(3):269-93.

49. Mansilha A, Sousa J. Pathophysiological mechanisms of chronic venous disease and implications for venoactive drug therapy. Int $\mathrm{J}$ Mol Sci. 2018;19(6):1669.

50. Michiels C, Bouaziz N, Remacle J. Role of the endothelium and blood stasis in the appearance of varicose veins. Int Angiol. 2002;21(1):1-8.

51. Takase S, Bergan JJ, Schmid-Schönbein G. Expression of adhesion molecules and cytokines on saphenous veins in chronic venous insufficiency. Ann Vasc Surg. 2000;14(5):427-35.

52. Howlader MH, Coleridge Smith PD. Symptoms of chronic venous disease and association with systemic inflammatory markers. J Vasc Surg. 2003;38(5):950-4.

53. Newland MR, et al. Neuropathy and gait disturbances in patients with venous disease: a pilot study. Arch Dermatol. 2009;145(4):485-6.

54. Shami SK, et al. Peripheral nerve function in chronic venous insufficiency. Eur J Vasc Surg. 1993;7(2):195-200.

55. Reinhardt F, et al. Peripheral neuropathy in chronic venous insufficiency. Muscle Nerve. 2000;23(6): 883-7.

56. Bradbury A, et al. The relationship between lower limb symptoms and superficial and deep venous reflux on duplex ultrasonography: the Edinburgh Vein Study. J Vasc Surg. 2000;32(5):921-31.

57. Duque MI, et al. Itch, pain, and burning sensation are common symptoms in mild to moderate chronic venous insufficiency with an impact on quality of life. J Am Acad Dermatol. 2005;53(3): 503-7.

58. Chiesa R, et al. Chronic venous disorders: correlation between visible signs, symptoms, and presence of functional disease. J Vasc Surg. 2007;46(2): 322-30.

59. Wrona $\mathrm{M}$, et al. Association of venous disorders with leg symptoms: results from the Bonn vein study 1. Eur J Vasc Endovasc Surg. 2015;50(3): 360-7.
60. Özdemir ÖÇ, Surmeli M. Conservative management of chronic venous insufficiency. In: Clinical physical therapy (2017). InTech, Houston.

61. Abu-Own A, Scurr JH, Coleridge Smith PD. Effect of leg elevation on the skin microcirculation in chronic venous insufficiency. J Vasc Surg. 1994;20(5):705-10.

62. Vaidyanathan $S$, et al. Chronic venous disorders of the lower limbs: a surgical approach. New York: Springer; 2014.

63. Nilsson A, Zhang Q, Styf J. The amplitude of pulsesynchronous oscillations varies with the level of intramuscular pressure in simulated compartment syndrome. J Exp Orthop. 2015;2(1):3.

64. Wiger P, Styf JR. Effects of limb elevation on abnormally increased intramuscular pressure, blood perfusion pressure, and foot sensation: an experimental study in humans. J Orthop Trauma. 1998;12(5):343-7.

65. Simka M et al. Calf muscle pump dysfunction in the patients with severe chronic venous insufficiency. Phlebolymphology. 2004. 47.

66. Kügler C, Strunk M, Rudofsky G. Venous pressure dynamics of the healthy human leg. Role of muscle activity, joint mobility and anthropometric factors. J Vasc Res. 2001;38(1):20-9.

67. Stein PD, Yaekoub AY, Ahsan ST, et al. Ankle exercise and venous blood velocity. Thromb Haemost. 2009;101(6):1100-3.

68. Kwon OY, Jung DY, Kim Y, Cho SH, Yi CH. Effects of ankle exercise combined with deep breathing on blood flow velocity in the femoral vein. Aust J Physiother. 2003;49(4):253-8.

69. Kropp AT, Meiss AL, Guthoff AE, et al. The efficacy of forceful ankle and toe exercises to increase venous return: a comprehensive Doppler ultrasound study. Phlebology. 2018;33(5):330-7.

70. O'Brien J, et al. Evaluating the effectiveness of a selfmanagement exercise intervention on wound healing, functional ability and health-related quality of life outcomes in adults with venous leg ulcers: a randomised controlled trial. Int Wound $\mathrm{J}$. 2017;14(1):130-7.

71. Yang D, Vandongen YK, Stacey MC. Effect of exercise on calf muscle pump function in patients with chronic venous disease. Br J Surg. 1999;86(3): 338-41.

72. Alguire P, Mathes B. Medical management of lower extremity chronic venous disease. UpToDate. 2012. 
73. Kan YM, Delis KT. Hemodynamic effects of supervised calf muscle exercise in patients with venous leg ulceration: a prospective controlled study. Arch Surg. 2001;136(12):1364-9.

74. Klonizakis $\mathrm{M}$, et al. Supervised exercise training as an adjunct therapy for venous leg ulcers: a randomized controlled feasibility trial. Br J Dermatol. 2018;178(5):1072-82.

75. Mutlak O, Aslam M, Standfield N. The influence of exercise on ulcer healing in patients with chronic venous insufficiency. Int Angiol. 2018;37(2):160-8.

76. Gianesini S, Tessari M, Bacciglieri P, et al. A specifically designed aquatic exercise protocol to reduce chronic lower limb edema. Phlebology. 2017;32(9): 594-600.

77. van Stralen KJ, Le Cessie S, Rosendaal FR, Doggen CJM. Regular sports activities decrease the risk of venous thrombosis. J Thromb Haemost. 2007;5(11): 2186-92.

78. Belgrado JP, Bourgeois P, Rõh N, Moraine JJ. Intermittent pneumatic compression in the treatment of Lymphedema-current state of knowledge. Eur J Lymphat Related Problems. 2007;17:4-11.

79. Comerota AJ. Intermittent pneumatic compression: physiologic and clinical basis to improve management of venous leg ulcers. J Vasc Surg. 2011;53(4): 1121-9.

80. Lim CS, Davies AH. Graduated compression stockings. CMAJ. 2014;186(10):E391-8.

81. Rabe E, et al. Indications for medical compression stockings in venous and lymphatic disorders: an evidence-based consensus statement. Phlebology. 2018;33(3):163-84.

82. Blazek C, Amsler F, Blaettler W, et al. Compression hosiery for occupational leg symptoms and leg volume: a randomized crossover trial in a cohort of hairdressers. Phlebology. 2013;28(5):239-47.

83. Schul MW, Eaton T, Erdman B. Compression versus sclerotherapy for patients with isolated refluxing reticular veins and telangiectasia: a randomized trial comparing quality-of-life outcomes. Phlebology. 2011;26(4):148-56.

84. Brizzio E, Amsler F, Lun B, Blättler W. Comparison of low-strength compression stockings with bandages for the treatment of recalcitrant venous ulcers. J Vasc Surg. 2010;51(2):410-6.

85. Wong IKY, Andriessen A, Charles HE, et al. Randomized controlled trial comparing treatment outcome of two compression bandaging systems and standard care without compression in patients with venous leg ulcers. J Eur Acad Dermatol Venereol. 2012;26(1):102-10.

86. Aguilar-Ferrándiz ME, Moreno-Lorenzo C, MataránPeñarrocha GA, et al. Effect of a mixed Kinesio taping-compression technique on quality of life and clinical and gait parameters in postmenopausal women with chronic venous insufficiency: doubleblinded, randomized controlled trial. Arch Phys Med Rehabil. 2014;95(7):1229-39.

87. Aguilar-Ferrándiz ME, Castro-Sánchez AM, Matarán-Peñarrocha GA, et al. A randomized controlled trial of a mixed Kinesio taping-compression technique on venous symptoms, pain, peripheral venous flow, clinical severity and overall health status in postmenopausal women with chronic venous insufficiency. Clin Rehabil. 2014;28(1): 69-81.

88. Berliner E, Ozbilgin B, Zarin DA. A systematic review of pneumatic compression for treatment of chronic venous insufficiency and venous ulcers. J Vasc Surg. 2003;37(3):539-44.

89. Smith PC, et al. Sequential gradient pneumatic compression enhances venous ulcer healing: a randomized trial. Surgery. 1990;108(5):871-5.

90. O'Meara S, et al. Compression for venous leg ulcers. Cochrane Database Syst Rev. 2012;11(11): CD000265.

91. Mariani F, Mattaliano V, Mosti G, et al. The treatment of venous leg ulcers with a specifically designed compression stocking kit. Phlebologie. 2008;37:191-7.

92. Jünger M, Wollina U, Kohnen R, Rabe E. Efficacy and tolerability of an ulcer compression stocking for therapy of chronic venous ulcer compared with a below-knee compression bandage: results from a prospective, randomized, multicentre trial. Curr Med Res Opin. 2004;20(10):1613-23.

93. Polignano R, Guarnera G, Bonadeo P. Evaluation of SurePress Comfort: a new compression system for the management of venous leg ulcers. J Wound Care. 2004;13(9):387-91.

94. Koskal C, Bozkurt AK. Combination of hydrocolloid dressing and medical compression stockings versus Unna's boot for the treatment of venous leg ulcers. Swiss Med Wkly. 2003;133(25-26):364-8.

95. Raju S, Hollis K, Neglen P. Use of compression stocking in chronic venous disease: patient compliance and efficacy. Ann Vasc Surg. 2007;21(6): 790-5.

96. Jull AB, Mitchell N, Arroll J, et al. Factors influencing concordance with compression stockings after 
venous leg ulcer healing. J Wound Care. 2004;13(3): 90-2.

97. Nicolaides AN, et al. Management of chronic venous disorders of the lower limbs: guidelines according to scientific evidence. Int Angiol. 2008;27(1):1-59.

98. Bush $\mathrm{R}$, et al. Recommendations for the medical management of chronic venous disease: the role of Micronized Purified Flavanoid Fraction (MPFF): recommendations from the Working Group in Chronic Venous Disease (CVD). Phlebology. 2017;32(1_suppl):3-19.

99. Gloviczki P, et al. The care of patients with varicose veins and associated chronic venous diseases: clinical practice guidelines of the Society for Vascular Surgery and the American Venous Forum. J Vasc Surg. 2011;53(5 Suppl):2s-48s.

100. Ulloa JH. Micronized purified flavonoid fraction (MPFF) for patient suffering from chronic venous disease: a review of new evidence. Adv Ther. 2019;36(Supp1):20-5.

101. das Graças CSM, Cyrino FZ, de Carvalho JJ, BlancGuillemaud V, Bouskela E. Protective effects of micronized purified flavonoid fraction (MPFF) on a novel experimental model of chronic venous hypertension. Eur J Vasc Endovasc Surg. 2018;55(5): 694-702.

102. Kakkos SK, Nicolaides AN. Efficacy of micronized purified flavonoid fraction (Daflon ${ }^{\circledR}$ ) on improving individual symptoms, signs and quality of life in patients with chronic venous disease: a systematic review and meta-analysis of randomized doubleblind placebo-controlled trials. Int Angiol. 2018;37(2):143-54.

103. Perrin M, Ramelet AA. Pharmacological treatment of primary chronic venous disease: rationale, results and unanswered questions. Eur J Vasc Endovasc Surg. 2011;41(1):117-25.

104. Rabe E, Agus GB, Roztocil K. Analysis of the effects of micronized purified flavonoid fraction versus placebo on symptoms and quality of life in patients suffering from chronic venous disease: from a prospective randomized trial. Int Angiol. 2015;34: 428-36.

105. Danielsson G, Jungbeck C, Peterson K, Norgren L. A randomised controlled trial of micronised purified flavonoid fraction vs placebo in patients with chronic venous disease. Eur J Vasc Endovasc Surg. 2002;23:73-6.

106. Gavrilov SG, Moskalenko YP, Karalkin AV. Effectiveness and safety of micronized purified flavonoid fraction for the treatment of concomitant varicose veins of the pelvis and lower extremities. Curr Med Res Opin. 2019;35(6):1019-26.

107. Carpentier P, van Bellen B, Karetova D, et al. Clinical efficacy and safety of a new 1000-mg suspension versus twice-daily 500-mg tablets of MPFF in patients with symptomatic chronic venous disorders: a randomized controlled trial. Int Angiol. 2017;36(5):402-9.

108. Ulloa JH, Guerra D, Cadavid LG, Fajardo D, Villarreal R, Bayon G, et al. Nonoperative approach for symptomatic patients with chronic venous disease: results from the VEIN Act program. Phlebolymphology. 2018;25(2):123.

109. Lishkov DE, Kirienko AI, Larionov AA, Chernookov AI. Patients seeking treatment for chronic venous disorders: Russian results from the VEIN Act program. Phlebolymphology. 2016;23(1):44.

110. Guilhou J-J, et al. Efficacy of Daflon $500 \mathrm{mg}$ in venous leg ulcer healing: a double-blind, randomized, controlled versus placebo trial in 107 patients. Angiology. 1997;48(1):77-85.

111. Smith PC. Daflon 500 mg and venous leg ulcer: new results from a meta-analysis. Angiology. 2005;56(6_suppl):S33-9.

112. Nicolaides AN. The benefit of micronized purified flavonoid fraction (MPFF) throughout the progression of chronic venous disease. Adv Ther. 2020;37(Suppl 1):1-5.

113. Bogachev VY, Boldin BV, Turkin PY. Administration of micronized purified flavonoid fraction during sclerotherapy of reticular veins and telangiectasias: results of the National, Multicenter, Observational Program VEIN ACT PROLONGED-C1. Adv Ther. 2018;35(7):1001-8.

114. Bogachev VY, Golovanova OV, Kuzhetsov AN, Shekoian AO. The DECISION Investigators Can micronized purified flavonoid fraction* (MPFF) improve outcomes of lower extremity varicose vein endovenous treatment? First results from the DECISION study. Phlebolymphology. 2013;20(4): 181-7.

115. Lyseng-Williamson KA, Perry CM. Micronised purified flavonoid fraction: a review of its use in chronic venous insufficiency, venous ulcers and haemorrhoids. Drugs. 2003;63(1):71-100.

116. Sintori CR. Aescin: pharmacology, pharmacokinetics and therapeutic profile. Pharm Res. 2001;44(3): 183-93.

117. Pittler MH, Ernst E. Horse chestnut seed extract for chronic venous insufficiency. Cochrane Database Syst Rev. 2012;11:CD003230. 
118. Gallelli L. Escin: a review of its anti-edematous, anti-inflammatory, and venotonic properties. Drug Des Dev Ther. 2019;13:3425-37.

119. Zhao SQ, Xu SQ, Cheng J, et al. Anti-inflammatory effect of external use of escin on cutaneous inflammation: possible involvement of glucocorticoids receptor. Chin J Nat Med. 2018;16(2):105-12.

120. Xin W, Zhang L, Sun F, et al. Escin exerts synergistic anti-inflammatory effects with low doses of glucocorticoids in vivo and in vitro. Phytomedicine. 2011;18(4):272-7.

121. Brunner F, Hoffmann C, Schuller-Petrovic S. Responsiveness of human varicose saphenous veins to vasoactive agents. $\mathrm{Br} \mathrm{J}$ Clin Pharmacol. 2001;51(3):219-24.

122. Diehm C, et al. Comparison of leg compression stocking and oral horse-chestnut seed extract therapy in patients with chronic venous insufficiency. Lancet. 1996;347(8997):292-4.

123. Suter A, Bommer S, Rechner J. Treatment of patients with venous insufficiency with fresh plant horse chestnut seed extract: a review of 5 clinical studies. Adv Ther. 2006;23(1):179-90.

124. Edem E, Kahyaoglu B, Çakar MA. Acute effusive pericarditis due to horse chestnut consumption. Am J Case Rep. 2016;17:305-8.

125. Alda O, Valero MS, Pereboom D. In vitro effect of calcium dobesilate on oxidative/inflammatory stress in human varicose veins. Phlebology. 2011;26(8):332-7.

126. Rabe E, Jaeger KA, Bulitta M, Pannier F. Calcium dobesilate in patients suffering from chronic venous insufficiency: a double-blind, placebo-controlled, clinical trial. Phlebology. 2011;26(4):162-8.

127. Rabe E, Ballarini S, Lehr L. A randomized, doubleblind, placebo-controlled, clinical study on the efficacy and safety of calcium dobesilate in the treatment of chronic venous insufficiency. Phlebology. 2015;31(4):264-74.

128. Flota-Cervera F, Flota-Ruiz C, Treviño C, Berber A. Randomized, double blind, placebo-controlled clinical trial to evaluate the lymphagogue effect and clinical efficacy of calcium dobesilate in chronic venous disease. Angiology. 2008;59(3):352-6.

129. Ciapponi A, Laffaire E, Roqué M. Calcium dobesilate for chronic venous insufficiency: a systematic review. Angiology. 2004;55(2):147-54.

130. Martínez-Zapata MJ, et al. A randomized, doubleblind multicentre clinical trial comparing the efficacy of calcium dobesilate with placebo in the treatment of chronic venous disease. Eur J Vasc Endovasc Surg. 2008;35(3):358-65.

131. Martinez-Zapata MJ, Vernooij RWM, Uriona Tuma $\mathrm{SM}$, et al. Phlebotonics for venous insufficiency. Cochrane Database Syst Rev. 2016;4:CD003229.

132. Stücker M, Rabe E, Meyer K, Ottillinger B, Schütt T. Therapeutic approach to chronic venous insufficiency: clinical benefits of red vine leaf extract AS 195 (Antistax ${ }^{\circledR}$ ). Pharmazie. 2019;74(4):193-200.

133. Grau M, Bölck B, Bizjak DA, Stabenow CJA, Bloch W. The red vine leaf extract AS195 increases nitric oxide synthase-dependent nitric oxide generation and decreases oxidative stress in endothelial and red blood cells. Pharmacol Res Perspect. 2016;4(1): e00213.

134. Nees S, Weiss DR, Reichenbach-Klinke E, et al. Protective effects of flavonoids contained in the red vine leaf on venular endothelium against the attack of activated blood components in vitro. Arzneimittelforschung. 2003;53(5):330-41.

135. Kalus U, Koscielny J, Grigorov A, et al. Improvement of cutaneous microcirculation and oxygen supply in patients with chronic venous insufficiency by orally administered extract of red vine leaves AS 195: a randomised, double-blind, placebocontrolled, crossover study. Drugs R D. 2004;5(2): 63-71.

136. Schaefer E, Peil H, Ambrosetti L, Petrini O. Oedema protective properties of the red vine leaf extract AS 195 (Folia vitis viniferae) in the treatment of chronic venous insufficiency: a 6 -week observational clinical trial. Arzneimittelforschung. 2003;53(4):243-6.

137. Kiesewetter H, Koscielny J, Kalus U, et al. Efficacy of orally administered extract of red vine leaf AS 195 (folia vitis viniferae) in chronic venous insufficiency (stages I-II): a randomized, double-blind, placebocontrolled trial. Arzneimittelforschung. 2000;50(2): 109-17.

138. Rabe E, Stücker E, Esperester A, Schäfer E, Ottillinger B. Efficacy and tolerability of a red vine leaf extract in patients suffering from chronic venous disease: results of a double-blind placebo-controlled study. Eur J Endovasc Surg. 2011;41(4):540-7.

139. Monsieur R, Van Snick G. Efficacy of the red vine leaf extract AS 195 in chronic venous insufficiency. Praxis (Bern 1994). 2006;95(6):187-90.

140. Azhdari M, Zilaee M, Karandish M, et al. Red vine leaf extract (AS 195) can improve some signs and symptoms of chronic venous insufficiency, a systematic review. Phytother Res. 2020;34(10): 2577-85. 
141. Jull A, Waters J, Arroll B. Pentoxifylline for treatment of venous leg ulcers: a systematic review. Lancet. 2002;359(9317):1550-4.

142. Krakauer T. Pentoxifylline inhibits ICAM-1 expression and chemokine production induced by proinflammatory cytokines in human pulmonary epithelial cells. Immunopharmacology. 2000;46(3): 253-61.

143. Smith PDC. Drug treatment of varicose veins, venous edema, and ulcers. In: Gloviczki P, editor. Handbook of venous and lymphatic disorders: guidelines of the American venous forum. Boca Raton: CRC Press; 2017. p. 391-8.

144. Jull AB, Arroll B, Parag V, Waters J. Pentoxifylline for treating venous leg ulcers. Cochrane Database Syst Rev. 2012;2012(12):CD001733.

145. Wollina U, Abdel-Naser MB, Mani R. A review of the microcirculation in skin in patients with chronic venous insufficiency: the problem and the evidence available for therapeutic options. Int J Low Extrem Wounds. 2006;593:169-80.

146. Belcaro G, Cesarone MR, Nicolaides $A N$, et al. Treatment of venous ulcers with pentoxifylline: a 6-month randomized, double-blind, placebo controlled trial. Angiology. 2002;53(Suppl 1):S45-7.

147. Parsa H, Zangivand AA, Hajimaghsoudi L. The effect of pentoxifylline on chronic venous ulcers. Wounds. 2012;24(7):190-4.

148. Nikolovska S, Pavlova L, Petrova N, Gocev G, Ivanovski M. Pentoxifylline: efficient in the treatment of venous ulcers in the absence of compression? Acta Dermatovenerol Croat. 2002;10(1):9-13.

149. Lacroix I, et al. First epidemiological data for venotonics in pregnancy from the EFEMERIS database. Phlebology. 2016;31(5):344-8.

150. Wittens C, et al. Editor's choice-management of chronic venous disease: clinical practice guidelines of the European Society for Vascular Surgery (ESVS). Eur J Vasc Endovasc Surg. 2015;49(6):678-737.

151. Kam MH, Tan SG. Results of long saphenous vein stripping. Singapore Med J. 2003;44(12):639-42.

152. Michaels JA, Brazier JE, Campbell WB, et al. Randomized clinical trial comparing surgery with conservative treatment for uncomplicated varicose veins. Br J Surg. 2006;93(2):175-81.

153. Krasznai AG, Sigterman TA, Houtermans-Auckel JP, et al. A randomised controlled trial comparing compression therapy after stripping for primary great saphenous vein incompetence. Phlebology. 2019;34(10):669-74.
154. Houtermans-Auckel JP, van Rossum E, Teijink JAW. To wear or not to wear compression stockings after varicose vein stripping: a randomised controlled trial. Eur J Vasc Endovasc Surg. 2009;38(3):387-91.

155. Kianifard B, Holdstock J, Allen C, et al. Randomized clinical trial of the effect of adding subfascial endoscopic perforator surgery to standard great saphenous vein stripping. Br J Surg. 2007;94(9): 1075-80.

156. Lin ZC, Loveland PM, Johnston RV, et al. Subfascial endoscopic perforator surgery (SEPS) for treating venous leg ulcers. Cochrane Database Syst Rev. 2019;2019(3):CD012164.

157. Zhan HT, Bush RL. A review of the current management and treatment options for superficial venous insufficiency. World J Surg. 2014;38(10): 2580-8.

158. de Zeeuw R, Wittens C, Loots M, Neumann M. Transilluminated powered phlebectomy accomplished by local tumescent anaesthesia in the treatment of tributary varicose veins: preliminary clinical results. Phlebology. 2007;22(2):90-4.

159. Scavée V, Lemaire E, Haxhe JP. Transilluminated powered phlebectomy: mid-term clinical experience. Int Angiol. 2005;24(1):75-9.

160. Luebke T, Brunkwall J. Meta-analysis of transilluminated powered phlebectomy for superficial varicosities. J Cardiovasc Surg (Torino). 2008;49(6): 757-64.

161. Chetter IC, Mylankal KJ, Hughes H, Fitridge R. Randomized clinical trial comparing multiple stab incision phlebectomy and transilluminated powered phlebectomy for varicose veins. Br J Surg. 2006;93(2):169-74.

162. Aremu MA, Mahendran B, Butcher W, et al. Prospective randomized controlled trial: conventional versus powered phlebectomy. J Vasc Surg. 2004;39(1):88-94.

163. Scavée V, Lesceu O, Theys S, et al. Hook phlebectomy versus transillumination powered phlebectomy for varicose vein surgery: early results. Eur J Vasc Endovasc Surg. 2003;25(5):473-5.

164. Carradice D, Mekako AI, Hatfield J, Chetter IC. Randomized clinical trial of concomitant or sequential phlebectomy after endovenous laser therapy for varicose veins. Br J Surg. 2009;96(4): 369-75.

165. Obi AT, Reames BN, Rook TJ, et al. Outcomes associated with ablation compared to combined ablation and transilluminated powered 
phlebectomy in the treatment of venous varicosities. Phlebology. 2016;31(9):618-24.

166. Kawai Y, Sugimoto M, Aikawa K, Komori K. Endovenous laser ablation with and without concomitant phlebectomy for the treatment of varicose veins: a retrospective analysis of 954 limbs. Ann Vasc Surg. 2020;66:344-50.

167. Mekako A, Hatfield J, Bryce J, et al. Combined endovenous laser therapy and ambulatory phlebectomy: refinement of a new technique. Eur J Vasc Endovasc Surg. 2006;32(6):725-9.

168. Parés JO, Juan J, Tellez R, et al. Varicose vein surgery: stripping versus the CHIVA method: a randomized controlled trial. Ann Surg. 2010;251(4): 624-31.

169. Carandina S, Mari C, De Palma M, et al. Varicose vein stripping vs haemodynamic correction (CHIVA): a long term randomised trial. Eur J Vasc Endovas Surg. 2008;35(2):230-7.

170. Zamboni P, Cisno C, Marchetti F, et al. Haemodynamic CHIVA correction surgery versus compression of primary venous ulcers: first year results. Phlebology. 2004;19(1):28-34.

171. Maeso J, Juan J, Maria Escribano J, et al. Comparison of clinical outcome of stripping and CHIVA for treatment of varicose veins in the lower extremities. Ann Vasc Surg. 2001;15(6):661-5.

172. González Cañas E, Florit López S, Vives Vilagut R, et al. A randomized controlled noninferiority trial comparing radiofrequency with stripping and conservative hemodynamic cure for venous insufficiency technique for insufficiency of the great saphenous vein. J Vasc Surg Venous Lymphat Disord, 2020. Online ahead of print.

173. Iborra-Ortega E, Barjau-Urrea E, Vila-Coll R, BallónCarazas H, Cairols-Castellote MA. Estudio comparativo de dos técnicas quirúrgicas en el tratamiento de las varices de las extremidades inferiores: resultados tras cinco años de seguimiento. Angiología. 2006;58(6):459-68.

174. Solís JV, Ribé L, Portero JL, Rio J. Stripping saphenectomy, CHIVA, and laser ablation for the treatment of the saphenous vein insufficiency. Amb Surg. 2009;15(1):11-4.

175. Faccini FP, Ermini S, Franceschi C. CHIVA to treat saphenous vein insufficiency in chronic venous disease: characteristics and results. J Vasc Bras. 2019;18:e20180099.

176. Milone M, Salvatore G, Maietta P, Sosa Fernandez LM, Milone F. Recurrent varicose veins of the lower limbs after surgery: role of the surgical technique (stripping vs CHIVA) and surgeon's experience. G Chir. 2011;32(11-12):460-3.

177. Vemulapalli S, et al. Systematic review and metaanalysis of endovascular and surgical revascularization for patients with chronic lower extremity venous insufficiency and varicose veins. Am Heart J. 2018;196:131-43.

178. Van den Bos R, et al. Endovenous therapies of lower extremity varicosities: a meta-analysis. J Vasc Surg. 2009;49(1):230-9.

179. Ahadiat O, Higgins S, Ly A, Nazemi A, Wysong A. Review of endovenous thermal ablation of the great saphenous vein. Derm Surg. 2018;44(5):679-88.

180. Paravatsu SCV, Horne M, Dodd PDF. Endovenous ablation therapy (laser or radiofrequency) or foam sclerotherapy versus conventional surgical repair for short saphenous varicose veins. Cochrane Database Syst Rev. 2016;2016(11):CD010878.

181. Brittenden J, Cotton SC, Elders A, et al. Clinical effectiveness and cost-effectiveness of foam sclerotherapy, endovenous laser ablation and surgery for varicose veins: results from the Comparison of LAser, Surgery, and foam Sclerotherapy (CLASS) randomised controlled trial. Health Technol Assess. $2015 ; 19(27): 1-342$.

182. Nandhra S, El-sheikha J, Carradice C, et al. A randomized clinical trial of endovenous laser ablation versus conventional survey for small saphenous varicose veins. J Vasc Surg. 2015;61(3):741-6.

183. Roopram AD, Lind MY, Van Brussel JP. Endovenous laser ablation versus conventional surgery in the treatment of small saphenous vein incompetence. J Vasc Surg Venous Lymphat Disord. 2013;1(4): 357-63.

184. Darwood RJ, Theivacumar N, Dellagrammaticas D, Mavor AID, Gough MJ. Randomized clinical trial comparing endovenous laser ablation with surgery for the treatment of primary great saphenous varicose veins. Br J Surg. 2008;95(3):294-301.

185. Park I. Initial outcomes of endovenous laser ablation with $1940 \mathrm{~nm}$ diode laser in the treatment of incompetent saphenous veins. Vascular. 2019;27(1):27-32.

186. Nishibe T, Nishibe M, Suzuki S, et al. Venous hemodynamic improvement after endovenous radiofrequency ablation of saphenous varicose veins. Int Angiol. 2017;36(1):64-8.

187. Lurie F, et al. Prospective randomised study of endovenous radiofrequency obliteration (closure) versus ligation and vein stripping (EVOLVeS): two- 
year follow-up. Eur J Vasc Endovasc Surg. 2005;29(1):67-73.

188. Perälä J, Rautio T, Biancari F, et al. Radiofrequency endovenous obliteration versus stripping of the long saphenous vein in the management of primary varicose veins: 3-year outcome of a randomized study. Ann Vasc Surg. 2005;19(5):669-72.

189. Subramonia S, Lees T. Randomized clinical trial of radiofrequency ablation or conventional high ligation and stripping for great saphenous varicose veins. Br J Surg. 2010;97(3):328-36.

190. de Almeida MC, de Aruda MA, Fukuda JM, et al. Randomized trial of radiofrequency ablation versus conventional surgery for superficial venous insufficiency: if you don't tell, they won't know. Clinics (Sao Paulo). 2016;71(11):650-6.

191. Sincos IR, Weinhardt Baptista AP, Coelho Neto F, et al. Prospective randomized trial comparing radiofrequency ablation and complete saphenous vein stripping in patients with mild to moderate chronic venous disease with a 3-year follow-up. Einstein (Sao Paulo). 2019;17(2):eAO4526.

192. Nesbitt C, Bedenis R, Bhattacharya V, Stansby G. Endovenous ablation (radiofrequency and laser) and foam sclerotherapy versus open surgery for great saphenous vein varices. Cochrane Database Syst Rev. 2014;2014(7):CD005624.

193. ElKaffas KH, ElKashef O, ElBaz W. Great saphenous vein radiofrequency ablation versus standard stripping in the management of primary varicose veins: a randomized clinical trial. Angiology. 2011;62(1): 49-54.

194. Rasmussen LH, Lawaetz M, Bjoern L, et al. Randomized clinical trial comparing endovenous laser ablation, radiofrequency ablation, foam sclerotherapy and surgical stripping for great saphenous varicose veins. Br J Surg. 2011;98(8):1079-87.

195. Rasmussen L, Lawaetz M, Serup J, et al. Randomized clinical trial comparing endovenous laser ablation, radiofrequency ablation, foam sclerotherapy, and surgical stripping for great saphenous varicose veins with 3-year follow-up. J Vasc Surg Venous Lymphat Disord. 2013;1(4):349-56.

196. Almeida JI, Kaufman J, Göckeritz O, et al. Radiofrequency endovenous ClosureFAST versus laser ablation for the treatment of great saphenous reflux: a multicenter, single-blinded, randomized study (RECOVER study). J Vasc Interv Radiol. 2009;20(6):752-9.

197. Shepherd AC, Gohel MS, Brown LC, et al. Randomized clinical trial of VNUS ClosureFAST radiofrequency ablation versus laser for varicose veins. Br J Surg. 2010;97(6):810-8.

198. Gale SS, Lee JN, Walsh ME, Wojnarowski DL, Comerota AJ. A randomized, controlled trial of endovenous thermal ablation using the 810-nm wavelength laser and the ClosurePLUS radiofrequency ablation methods for superficial venous insufficiency of the great saphenous vein. J Vasc Surg. 2010;52(3):645-50.

199. Nordon IM, Hinchliffe RJ, Brar R, et al. A prospective double-blind randomized controlled trial of radiofrequency versus laser treatment of the great saphenous vein in patients with varicose veins. Ann Surg. 2011;254(6):876-81.

200. Tesmann JP, Thierbach H, Dietrich A, et al. Radiofrequency induced thermotherapy (RFITT) of varicose veins compared to endovenous laser treatment (EVLT): a non-randomized prospective study concentrating on occlusion rates, side-effects and clinical outcome. Eur J Dermatol. 2011;21(6): 945-51.

201. Bozoglan O, Mese B, Eroglu E, Ekerbiçer HC, Yasim A. Comparison of endovenous laser and radiofrequency ablation in treating varices in the same patient. J Lasers Med Sci. 2017;8(1):13-6.

202. Hamann SAS, Timmer-de Mik L, Fritschy WM, et al. Randomized clinical trial of endovenous laser ablation versus direct and indirect radiofrequency ablation for the treatment of great saphenous varicose veins. Br J Surg. 2019;106(8):998-1004.

203. Chait J, Kibrik P, Alsheekh A, et al. Radiofrequency ablation increases the incidence of endothermal heat-induced thrombosis. Ann Vasc Surg. 2020;62: 263-7.

204. Lawaetz M, Serup J, Lawaetz B, et al. Comparison of endovenous ablation techniques, foam sclerotherapy and surgical stripping for great saphenous varicose veins: extended 5-year follow-up. Int Angiol. 2017;36(3):281-8.

205. Redondo P, Cabrera J. Microfoam sclerotherapy. Sem Cutan Med Surg. 2005;24(4):175-83.

206. Labas P, Cambal M. Profuse bleeding in patients with chronic venous insufficiency. Int Angiol. 2007;26(1):64-6.

207. Biemans AAM, Kockaert M, Akkersdijk GP, et al. Comparing endovenous laser ablation, foam sclerotherapy, and conventional surgery for great saphenous varicose veins. J Vasc Surg. 2013;58(3): 727-34.

208. Shadid N, Ceulen R, Nelemans P, et al. Randomized clinical trial of ultrasound-guided foam 
sclerotherapy versus surgery for the incompetent great saphenous vein. $\mathrm{Br} \mathrm{J}$ Surg. 2012;99(8): 1062-70.

209. Lattimer CR, Azzam M, Kalodiki E, et al. Cost and effectiveness of laser with phlebectomies compared with foam sclerotherapy in superficial venous insufficiency. Early results of a randomised controlled trial. Eur J Vasc Endovasc Surg. 2012;43(5): 594-600.

210. Campos W, Ohashi Torres I, Simão da Silva E, Benaduce Casella I, Puech-Leão P. A prospective randomized study comparing polidocanol foam sclerotherapy with surgical treatment of patients with primary chronic venous insufficiency and ulcer. Ann Vasc Surg. 2015;29(6):1128-35.

211. van der Velden SK, Biemans AAM, De Maeseneer MGR, et al. Five-year results of a randomized clinical trial of conventional surgery, endovenous laser ablation and ultrasound-guided foam sclerotherapy in patients with great saphenous varicose veins. Br J Surg. 2015;102(10):1184-94.

212. Figueiredo M, Araüjo S, Barros N, Miranda F. Results of surgical treatment compared with ultrasoundguided foam sclerotherapy in patients with varicose veins: a prospective randomised study. Eur J Vasc Endovasc Surg. 2009;38(6):758-63.

213. Venermo M, Saarinen J, Eskelinen E, et al. Randomized clinical trial comparing surgery, endovenous laser ablation and ultrasound-guided foam sclerotherapy for the treatment of great saphenous varicose veins. Br J Surg. 2016;103(11):1438-44.

214. Tassie E, Scotland G, Brittenden J, et al. Cost-effectiveness of ultrasound-guided foam sclerotherapy, endovenous laser ablation or surgery as treatment for primary varicose veins from the randomized CLASS trial. Br J Surg. 2014;101(12):1532-40.

215. Bountouroglou DG, Azzam M, Kakkos SK, et al. Ultrasound-guided foam sclerotherapy combined with sapheno-femoral ligation compared to surgical treatment of varicose veins: early results of a randomised controlled trial. Eur J Endovasc Surg. 2006;31(1):93-100.

216. Vähäho S, Halmesmäki K, Albäck A, Saarinen E, Venermo M. Five-year follow-up of a randomized clinical trial comparing open surgery, foam sclerotherapy and endovenous laser ablation for great saphenous varicose veins. Br J Surg. 2018;105(6): 686-91.

217. Gibson K, Gunderson K. Liquid and foam sclerotherapy for spider and varicose veins. Surg Clin N Am. 2018;98(2):415-29.
218. O'Donnell TF, Eaddy M, Raju A, et al. Assessment of thrombotic adverse events and treatment patterns associated with varicose vein treatment. J Vasc Surg Venous Lymphat Disord. 2015;3(1):27-35.

219. Willenburg T, Smith PC, Shepherd A, et al. Visual disturbance following sclerotherapy for varicose veins, reticular veins and telangiectasias: a systematic literature review. Phlebology. 2013;28(3): 123-31.

220. Hamel-Desnos C, Allaert FA. Liquid versus foam sclerotherapy. Phlebology. 2009;24(6):240-6.

221. Bi M, Li D, Chen Z, et al. Foam sclerotherapy compared with liquid sclerotherapy for the treatment of lower extremity varicose veins: a protocol for systematic review and meta analysis. Medicine (Baltimore). 2020;99(22):e20332.

222. Kaygin MA, Halici U. Evaluation of liquid or foam sclerotherapy in small varicose veins (CEAP C1) with venous clinical severity score. Rev Assoc Med Bras (1992). 2018;64(12):1117-21.

223. Alòs J, Carreño P, López JA. Efficacy and safety of sclerotherapy using polidocanol foam: a controlled clinical trial. Eur J Vasc Endovasc Surg. 2006;31(1): $101-7$.

224. Ukritmanoroat T. Comparison of efficacy and safety between foam sclerotherapy and conventional sclerotherapy: a controlled clinical trial. J Med Assoc Thai. 2011;94(Suppl 2):S35-40.

225. Rabe E, Otto J, Schliephake D, Pannier F. Efficacy and safety of great saphenous vein sclerotherapy using standardised polidocanol foam (ESAF): a randomised controlled multicentre clinical trial. Eur J Vasc Endovasc Surg. 2008;35(2):238-45.

226. Ouvry P, Allaert FA, Desnos P, Hamel-Desnos C. Efficacy of polidocanol foam versus liquid in sclerotherapy of the great saphenous vein: a multicentre randomised controlled trial with a 2-year followup. Eur J Vasc Endovasc Surg. 2008;36(3):366-70.

227. Hamel-Desnos C, Desnos P, Wollmann JC, et al. Evaluation of the efficacy of polidocanol in the form of foam compared with liquid form in sclerotherapy of the greater saphenous vein: initial results. Dermatol Surg. 2003;29(12):1170-5.

228. Uncu H. Sclerotherapy: a study comparing polidocanol in foam and liquid form. Phlebology. 2010;25(1):44-9.

229. Almeida JI, et al. First human use of cyanoacrylate adhesive for treatment of saphenous vein incompetence. J Vasc Surg Venous Lymphat Disord. 2013;1(2):174-80. 
230. Bellam Premnath KP, Joy B, Raghavendra VA, Toms A, Sleeba T. Cyanoacrylate adhesive embolization and sclerotherapy for primary varicose veins. Phlebology. 2018;33(8):547-57.

231. Tok M, Tüydeş O, Yüksel A, Şenol S, Akarsu S. Earlyterm outcomes for treatment of saphenous vein insufficiency with n-butyl cyanoacrylate: a novel, non-thermal, and non-tumescent percutaneous embolization technique. Heart Surg Forum. 2016;19(3):E118-122.

232. Yang GK, Parapini M, Gagnon J, Chen JC. Comparison of cyanoacrylate embolization and radiofrequency ablation for the treatment of varicose veins. Phlebology. 2019;34(4):278-83.

233. Morrison $\mathrm{N}$, et al. Randomized trial comparing cyanoacrylate embolization and radiofrequency ablation for incompetent great saphenous veins (VeClose). J Vasc Surg. 2015;61(4):985-94.

234. Ovalı C, Sevin MB. Twelve-month efficacy and complications of cyanoacrylate embolization compared with radiofrequency ablation for incompetent great saphenous veins. J Vasc Surg Venous Lymphat Disord. 2019;7(2):210-6.

235. Bademci MŞ, Kocaaslan C, Aldag M, et al. Singlecenter retrospective review of early outcomes of radiofrequency ablation versus cyanoacrylate ablation of isolated great saphenous vein insufficiency. J Vasc Surg Venous Lymphat Disord. 2019;7(4): 480-5.

236. Ay Y, Gunes E, Turkkolu ST, et al. Comparative efficacy and life quality effects of surgical stripping, radiofrequency ablation, and cyanoacrylate embolization in patients undergoing treatment for great saphenous vein insufficiency. Phlebology. 2021;36(1):54-62.

237. Koramaz I, El Kılıç H, Gökalp F, et al. Ablation of the great saphenous vein with nontumescent n-butyl cyanoacrylate versus endovenous laser therapy. J Vasc Surg Venous Lymphat Disord. 2017;5(2): 210-5.

238. Çalık ES, Arslan Ü, Erkut B. Ablation therapy with cyanoacrylate glue and laser for refluxing great saphenous veins: a prospective randomised study. Vasa. 2019;48(5):405-12.

239. Bissacco D, Stegher S, Calliari FM, Viani MP. Saphenous vein ablation with a new cyanoacrylate glue device: a systematic review on 1000 cases. Minim Invasive Ther Allied Technol. 2019;28(1): 6-14.

240. McGuinness B, Elias F, Ali KP. A comparison of duplex ultrasound findings after cyanoacrylate embolization versus endovenous laser ablation of the great saphenous vein. J Vasc Surg Venous Lymphat Disord. 2019;7(6):824-31.

241. Almeida JI, Murray SP, Romero ME. Saphenous vein histopathology 5.5 years after cyanoacrylate closure. J Vasc Surg Venous Lymphat Disord. 2020;8(2):280-4.

242. van Eekeren RR, et al. Endovenous mechanochemical ablation of great saphenous vein incompetence using the ClariVein device: a safety study. J Endovasc Ther. 2011;18(3):328-34.

243. Mohamed AH, Leung C, Wallace T, et al. A randomized controlled Trial of endovenous laser ablation versus mechanochemical ablation with ClariVein in the management of superficial venous incompetence (LAMA trial). Ann Surg. 2020. https://doi.org/10.1097/SLA.0000000000003749.

244. Vähäaho S, Mahmoud $\mathrm{O}$, Halmesmäki $\mathrm{K}$, et al. Randomized clinical trial of mechanochemical and endovenous thermal ablation of great saphenous varicose veins. Br J Surg. 2019;106(5):548-54.

245. Tawfik AM, Sorour WA, El-Laboudy ME. Laser ablation versus mechanochemical ablation in the treatment of primary varicose veins: a randomized clinical trial. J Vasc Surg Venous Lymphat Disord. 2020;8(2):211-5.

246. Holewijn S, van Eekeren RRJP, Vahl A, et al. Twoyear results of a multicenter randomized controlled trial comparing mechanochemical endovenous ablation to radiofrequency ablation in the treatment of primary great saphenous vein incompetence (MARADONA trial). J Vasc Surg Venous Lymphat Disord. 2019;7(3):364-74.

247. Bootun R, Lane TRA, Dharmarajah B, et al. Intraprocedural pain score in a randomised controlled trial comparing mechanochemical ablation to radiofrequency ablation: the multicenter Venefit ${ }^{\mathrm{TM}}$ versus ClariVein ${ }^{\circledR}$ for varicose veins trial. Phlebology. 2016;31(1):61-5.

248. Witte ME, Zeebregts CJ, de Borst GJ, Reijnen MMPJ, Boersma D. Mechanochemical endovenous ablation of saphenous veins using the ClariVein: a systematic review. Phlebology. 2017;32(10):649-57.

249. Bishawi M, Bernstein R, Boter $M$, et al. Mechanochemical ablation in patients with chronic venous disease: a prospective multicenter report. Phlebology. 2014;29(6):397-400.

250. van Eekeren RRJP, Boersma D, Holewijn S, et al. Mechanochemical endovenous ablation for the treatment of great saphenous vein insufficiency. J Vasc Surg Venous Lymphat Disord. 2014;2(3): 282-8. 
251. Elias S, Raines JK. Mechanochemical tumescentless endovenous ablation: final results of the initial clinical trials. Phlebology. 2012;27(2):67-72.

252. Deijen CL, Schreve MA, Bosma J, et al. Clarivein mechanochemical ablation of the great and small saphenous vein: early treatment outcomes of two hospitals. Phlebology. 2016;31(3):192-7.

253. Mohamed AH, Leung C, Wallace $\mathrm{T}$, et al. Mechanochemical ablation for the treatment of superficial venous incompetence: a cohort study of a single centre's early experience. Phlebology. 2019;34(7):466-73.

254. Kim PS, Bishawi M, Draughn D, et al. Mechanochemical ablation for symptomatic great saphenous vein reflux: a two-year follow-up. Phlebology. 2017;32(1):43-8.

255. Witte ME, Holewijn S, van Eekeren RR. Midterm outcome of mechanochemical endovenous ablation for the treatment of great saphenous vein insufficiency. J Endovasc Ther. 2017;24(1):149-55. 